Research Article

\title{
Dynamic Study of VSA and TSA Processes for VOCs Removal from Air
}

\author{
Rawnak Talmoudi $\mathbb{D}^{1},{ }^{1}$ Amna AbdelJaoued, ${ }^{1}$ and Mohamed Hachemi Chahbani ${ }^{1,2}$ \\ ${ }^{1}$ Laboratoire de Recherche Génie des procédés et systèmes industriels, Ecole Nationale d'Ingénieurs de Gabès, Université de Gabès, \\ Gabès, Tunisia \\ ${ }^{2}$ Institut Supérieur des Sciences Appliquées et de Technologie de Gabès, Rue Omar Ibn Elkhattab, Zrig, Gabès 6029, Tunisia \\ Correspondence should be addressed to Rawnak Talmoudi; talmoudirawnak@hotmail.com
}

Received 26 April 2018; Revised 3 August 2018; Accepted 4 September 2018; Published 24 September 2018

Academic Editor: Doraiswami Ramkrishna

Copyright (c) 2018 Rawnak Talmoudi et al. This is an open access article distributed under the Creative Commons Attribution License, which permits unrestricted use, distribution, and reproduction in any medium, provided the original work is properly cited.

\begin{abstract}
Volatile organic compounds are air pollutants that necessitate to be eliminated for health and environment concerns. In the present paper, two VOCs, that is, dichloromethane and acetone are recovered by adsorption on activated carbon from a nitrogen gas stream. Experimental adsorption isotherms of the two VOCs are determined at three different temperatures 298, 313, and $323 \mathrm{~K}$ by the dynamic column breakthrough method. The dynamic mathematical model succeeds to predict satisfactorily the experimental breakthrough curves for pure VOCs and different binary mixtures for various conditions. Thus, the validated dynamic mathematical model has been used as a simulation tool for optimization purposes of VSA and TSA processes in order to achieve the highest performances under the given constraints. The effects of the adsorption step duration, the vacuum pressure, and the desorption temperature on the recovery of dichloromethane and acetone have been studied. A recovery of $100 \%$ of the two VOCs could be attained. However, the adsorption step duration should be determined precisely so as not to affect the recovery and alter the quality of air being purified due to the breakthrough of VOCs. The vacuum pressure and the desorption temperature should be carefully chosen in order to both reduce the energy consumption and shorten the purge step duration. Regeneration by hot nitrogen stream seems to be more efficient than regeneration by reducing pressure.
\end{abstract}

\section{Introduction}

Volatile organic compounds (VOCs) constitute a heterogeneous group of substances with different physical and chemical behaviours, including alkanes, ketones, aromatics, paraffins, olefins, alcohols, ethers, esters, and halogenated and sulfur hydrocarbons $[1,2]$. VOCs are emitted from chemical industry gaseous effluents, oil sands process, food industries, paint industries, and petrochemical industries [2].

Dichloromethane, acetone, and ethyl formate are widely used in the oil sands process for the extraction of the bitumen from the oil sands [3]. After the separation of bitumen, these VOCs should be recovered to avoid serious effects on human health and environment.

Tropospheric ozone is not emitted into the air, but actually formed in the atmosphere through a photochemical process for which VOCs play a significant role. VOCs in the air react with oxides of nitrogen $\mathrm{NO}_{x}$ in the presence of sunlight to form ozone. Tropospheric ozone has to be distinguished from ozone in the stratosphere which is part of what is commonly referred to as the "ozone layer" helping to block the sun's ultraviolet radiation. Unfortunately, most VOCs produce ozone, which inhabits the troposphere. Troposphere or ground level ozone is a harmful, photochemical oxidant that significantly contributes to the formation of smog. It is regularly measured as an indicator of smog levels in the atmosphere. Preventive measures should be taken to avoid serious problems for those with asthma and respiratory conditions for days when ozone level is high. Ozone concentrations of even $0.08 \mathrm{ppm}$ contributed to lung disease and pulmonary function deterioration in children. There is evidence that prolonged exposure to ozone causes permanent damage to lung tissue and interferes with the functioning of the immune system. Other consequences of 
excessive ozone levels can include damage to the ecosystem including the retardation of plant growth and crop yields [4].

Being a precursor of photochemical oxidants, eye irritant and a suspected toxicant of respiratory, gastrointestinal and nervous system, acetone may have detrimental effects on human health and environment [5]. Human studies have observed associations between occupational exposure to dichloromethane and increased risk for several specific cancers, including brain cancer, liver and biliary tract cancer, non-Hodgkin lymphoma, and multiple myeloma [6].

Results from experimental studies in humans indicate that acute neurobehavioral deficits, measured, for example, by psychomotor tasks, tests of hand-eye coordination, visual evoked response changes, and auditory vigilance, may occur at concentrations $>200 \mathrm{ppm}$ with $4-8 \mathrm{hr}$ of exposure [7].

As a result, the control of dichloromethane, acetone, and any VOC exhausts in ambient air is considered imperative.

There are several methods used to reduce the VOCs such as absorption, adsorption, incineration, catalytic oxidation, biological treatment, ionization, photocatalysis. Adsorption onto activated carbon is a highly efficient and relatively inexpensive technique employed for the removal and recovery of VOCs from air [8-11].

The most known cyclic adsorption operation is pressure swing adsorption (PSA) $[12,13]$, vacuum swing adsorption (VSA), and temperature swing adsorption (TSA) [14, 15]. The difference between these processes is their adsorption and regeneration mode. In TSA processes, the temperature changes in each step with the low temperature upon adsorption and the high temperature in regeneration. The PSA technique depends on the pressure where the adsorption step is carried out at the high pressure and the regeneration operation is at atmospheric pressure.

Many studies of PSA, TSA, and VSA have been widely investigated for recovery of VOCs from polluted air streams [16-18]. There are more papers dealing with dichloromethane $[19,20]$ than acetone [21]. Each VOC is treated separately and works dealing with mixtures of the two VOCs are lacking in the literature. In general, these works are just limited to the experimental determination of breakthrough curves and experiments of regeneration; the cyclic steady state is not considered. Furthermore, the models used for simulation often use simplifying assumptions such as negligible pressure drop, isothermal conditions.

It has to be noted that the adsorption step of VOCs has been widely studied in the literature for different objectives (selection of the appropriate adsorbent, effect of operating conditions). However, the regeneration step has been rarely investigated despite its importance for the performance of the whole process. Regeneration could be done by reducing the pressure or increasing the temperature. Regeneration is crucial so as to ensure that the adsorption process remains attractive in comparison with other processes. It has a notable effect on the duration of the total cycle and hence affects the size and the number of beds of the purification installation.

The principal aim of this work is to design an adsorption based separation process (Vacuum Swing Adsorption and temperature swing adsorption) for recovering two VOCs, that is, dichloromethane and acetone, used extensively in oil sands process. The design of the process involves experimental determination of equilibrium isotherms of the two VOCs on a commercial activated carbon using the dynamic column breakthrough method and the realization of a simulation tool. The validated simulation tool, considering minimum simplifying assumptions, is to be used for testing the technical feasibility and optimizing the VSA and TSA process through varying the operating parameters. Results of simulations should give elements of responses concerning the most appropriate process to be used for the present case, that is, the capture of acetone and dichloromethane.

\section{Experiments}

The adsorbent used is a commercial activated carbon supplied by CECA (Communauté Européenne pour le Charbon et l'Acier); it is of plant origin and precisely of maritime pine.

The apparent density and the BET Surface are $250 \mathrm{~kg} \cdot \mathrm{m}^{3}$ and $1706 \mathrm{~m}^{2} \cdot \mathrm{g}^{-1}$, respectively. The specific surface area of the adsorbent is determined by measuring a $\mathrm{N}_{2}$ isotherm at $77 \mathrm{~K}$ using an ASAP 2020 apparatus from Micromeritics. The specific surface area is calculated according to the BET method [22].

The measurements of pure species adsorption equilibrium isotherms and breakthrough curves of pure components and binary mixtures of VOCs vapors are performed with a dynamic adsorption unit.

Figure 1 shows the experimental setup used. VOCs at the liquid state (a pure component or a binary mixture) are injected by one or two syringe pumps in the vaporization column. At the exit of the column, the liquid is completely vaporized.

A continuous nitrogen gas stream (inert gas) fixed by a mass flow controller (Brooks Instruments) is introduced in the unit. Nitrogen is then mixed with the VOCs vapor exiting the vaporization column before entering the adsorption column at a superficial velocity of $0.17 \mathrm{~m} \cdot \mathrm{s}^{-1}$. The amount of activated carbon packed in the column is $2 \mathrm{~g}$. Experiments are carried out at atmospheric pressure and a temperature of $25^{\circ} \mathrm{C}$. The column is made of stainless steel and has a height of $10 \mathrm{~cm}$ and an internal diameter of $1 \mathrm{~cm}$. The temperature of experiments is controlled by a thermostatic enclosure. Pure components isotherms are determined for concentrations ranging from 500 to $12000 \mathrm{ppm}$ on activated carbon at atmospheric pressure and at three temperatures, $298 \mathrm{~K}, 313 \mathrm{~K}$, and $323 \mathrm{~K}$. Breakthrough curves for single solvent vapor of dichloromethane and acetone are carried out at $298 \mathrm{~K}, 313 \mathrm{~K}$, and $323 \mathrm{~K}$ under atmospheric pressure. Concentrations of solvent vapors at the inlet of the bed are set from 500 to $12000 \mathrm{ppm}$.

Four different breakthrough curves of dichloromethane/ acetone vapor mixtures at various inlet concentrations, 3000 ppm/1500 ppm, 2000 ppm/500 ppm, 500 ppm/2000 ppm, and $750 \mathrm{ppm} / 400 \mathrm{ppm}$, are performed on activated carbon at $298 \mathrm{~K}$ and at atmospheric pressure.

The variation of VOCs concentrations with time at the exit of the adsorption bed are measured by a Gas 


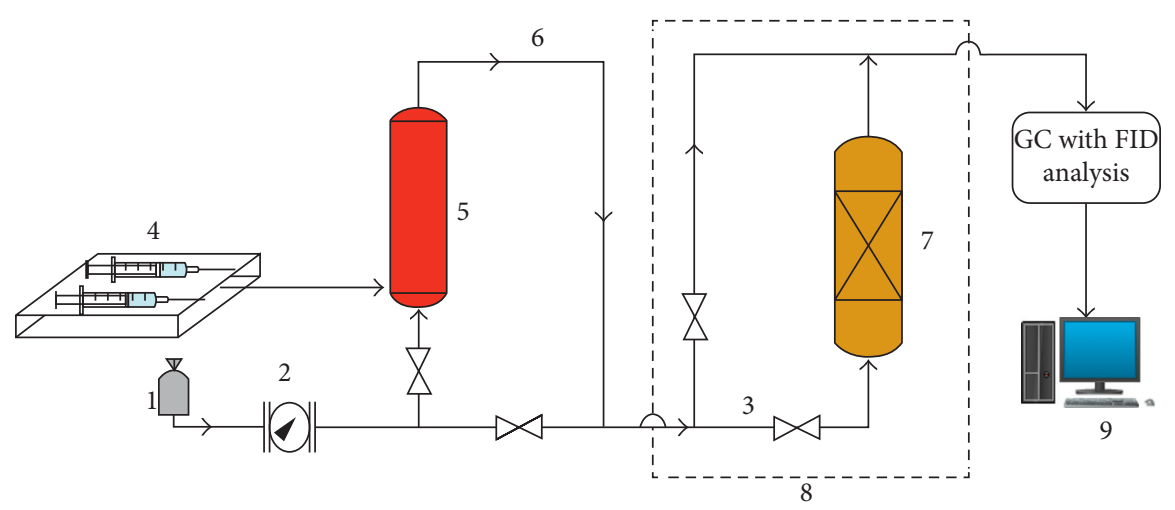

FIgURE 1: Schematic diagram of experimental unit for adsorption of VOCs vapors over activated carbon. (1) Feed nitrogen; (2) mass flow controller; (3) pure N2 stream; (4) syringe pump; (5) evaporator column; (6) main stream; (7) adsorption column; (8) thermostatic enclosure; (9) gas chromatography; (10) acquisition software.

Chromatograph (CompactGC ${ }^{4.0}$ Interscience, G.A.S)) combined with a flame ionization detector (FID, sampling loop $20 \mu \mathrm{L}$, sampling from the main stream by vacuum pump). The sample is transported into chromatographic column which has an inner diameter of $0.32 \mathrm{~mm}$ and a length of $10 \mathrm{~mm}$, and then, the sample is separated by the GC column coated with Poraplot $Q$ stationary phase. The time for analysis of the single isotherm adsorption is about $3 \mathrm{~min}$ for both dichloromethane and acetone. Breakthrough curves were obtained by plotting the concentrations of each VOC at the bed exit over time. After each adsorption step, the feed stream is changed to pure nitrogen so as to regenerate the fixed adsorption bed.

\section{Mathematical modeling}

The mathematical model for a packed adsorption bed, assuming nonisothermal operation, involves mass balances for the bulk fluid phase, mass transfer kinetics, gas-phase and solid phase heat balances, and a momentum balance.

The following assumptions are considered:

(i) Non isothermal operation

(ii) Ideal gas behavior for the gas phase

(iii) Constant void fraction and velocity of gas

(iv) Radial concentration and temperature gradients negligible

(v) Diffusion and mass transfer within a particle was described by linear driving force (LDF)

(vi) Absence of temperature gradients within the solid particle

3.1. Mass Balance. A differential fluid phase mass balance for the component $i$ is given by the following axially dispersed plug flow equation [23]:

$$
-D_{z} \frac{\partial^{2} c_{i}}{\partial Z^{2}}+\frac{\partial c_{i}}{\partial t}+\frac{\partial\left(v_{\mathrm{g}} c_{i}\right)}{\partial Z}+\frac{(1-\varepsilon)}{\varepsilon} \rho_{\mathrm{p}} \frac{\partial q_{i}}{\partial t}=0 \quad i=1,2
$$

The overall mass balance for the bulk gas is given by

$$
\frac{\partial C}{\partial t}+\frac{\partial\left(v_{\mathrm{g}} C\right)}{\partial Z}+\frac{(1-\varepsilon)}{\varepsilon} \rho_{\mathrm{p}} \sum_{i=1}^{n} \frac{\partial q_{i}}{\partial t}=0
$$

where $v_{\mathrm{g}}$ is the interstitial gas velocity, $\varepsilon$ is the bed void fraction, $C$ is total bulk concentration, $\rho_{\mathrm{p}}$ is the particle density, $q_{i}$ is the adsorbed concentration of component $i, Z$ is the axial co-ordinate, and $D_{z}$ is the axial dispersion coefficient, which can be estimated by [24]

$$
D_{z}=0.73 D_{\mathrm{m}}+0.5 \frac{d_{\mathrm{p}} \mu_{i}}{1+9.7\left(D_{\mathrm{m}} / d_{\mathrm{p}} \mu_{i}\right)},
$$

where $d_{\mathrm{p}}$ is the particle diameter, $\mu_{i}$ is the interstitial velocity, and $D_{\mathrm{m}}$ is the molecular diffusivity that can be estimated from the Chapman-Enskog equation [25].

3.2. Momentum Balance. The pressure drop along the bed was determined from the Ergun equation [23]:

$$
\frac{\partial P}{\partial Z}=150 \frac{(1-\varepsilon)^{2}}{\varepsilon^{2} d_{\mathrm{p}}^{2}} \mu v_{\mathrm{g}}+1.75 \frac{(1-\varepsilon)}{\varepsilon d_{\mathrm{p}}} \rho_{\mathrm{g}} v_{\mathrm{g}}^{2},
$$

where $\mu$ is the gas mixture viscosity, $\rho_{\mathrm{g}}$ is the gas density, and $d_{\mathrm{p}}$ is the particle diameter.

3.3. Mass Transfer Kinetics. The mass transfer rate between the gas and solid phases is given the linear driving force (LDF) model represented by the following equations [26]:

$$
\frac{\partial q_{i}}{\partial t}=k_{i, \mathrm{LDF}}\left(q_{i}^{*}-q_{i}\right) \quad i=1,2,
$$

where

$$
k_{i, \mathrm{LDF}}=\frac{15 D_{\mathrm{e}, i}}{r_{\mathrm{p}}^{2}},
$$

where $k_{\mathrm{i}, \mathrm{LDF}}$ is the mass transfer coefficient, $q_{i}^{*}$ is the loading of component $i, D_{\mathrm{e}, i}$ is the effective diffusivity of component $i$, and $r_{\mathrm{p}}$ is the particle radius.

It is common practice to predict mixture isotherms from pure component isotherms. The multicomponent extension of Langmuir-Freundlich model of dichloromethane and 
acetone is used based on parameters obtained from pure components. The model is represented by the following equations [27]:

$$
\begin{aligned}
q_{i}^{*} & =q_{\mathrm{m}, i} \frac{\left(b_{i} C_{i}\right)^{k_{3 i}}}{1+\sum_{j}\left(b_{j} C_{j}\right)^{k_{3 i}}} \quad i, j=1,2, \\
b_{i} & =k_{1 i} \exp \frac{k_{2 i}}{T}
\end{aligned}
$$

where $q_{m, i}$ is the saturation capacity, $b_{\mathrm{i}}, k_{1 i}, k_{2 i}$, and $k_{3 i}$ are the Langmuir-Freundlich equation parameters for component $i$.

The fit between experimental data and isotherms equation is calculated according to Equation (9) which indicated the minimum sum of squares SS at three temperatures of pure 2 VOCs:

$$
\operatorname{SS}(\%)=\sum_{T_{i}}^{T_{3}} \sum_{j=1}^{N}\left(q_{\exp , i}-q_{\bmod , i}\right)^{2}
$$

where $q_{\text {exp }, i}$ and $q_{\text {mod, } i}$ are the experimental and predicted amounts adsorbed, respectively, $T_{1}$ to $T_{3}$ are the three tested temperatures, $j$ is the number of points per isotherm and gas component, $i$ represents the component (dichloromethane and acetone), and $\mathrm{N}$ is the total number of experimental data points.

3.4. Heat Balance for the Gas Phase. The gas-phase energy balance includes convection of energy, axial thermal conduction, accumulation of heat, gas-solid heat transfer, and gas-wall heat transfer. The governing partial differential equation is as follows [28]:

$$
\begin{gathered}
C_{\mathrm{pg}} \rho_{\mathrm{g}} \frac{\partial T_{\mathrm{g}}}{\partial t}-\lambda_{\mathrm{L}} \frac{\partial^{2} T_{\mathrm{g}}}{\partial Z^{2}}+\rho_{\mathrm{g}} C_{\mathrm{pg}} \frac{\partial\left(v_{\mathrm{g}} T_{\mathrm{g}}\right)}{\partial Z}+\left(\frac{1-\varepsilon}{\varepsilon}\right) a_{\mathrm{s}} h_{\mathrm{f}}\left(T_{\mathrm{g}}-T_{\mathrm{s}}\right) \\
+\frac{4 h_{\mathrm{w}}}{\varepsilon_{\mathrm{b}} d_{\text {int }}}\left(T_{\mathrm{g}}-T_{\mathrm{w}}\right)=0
\end{gathered}
$$

where $C_{\mathrm{pg}}$ and $C_{\mathrm{ps}}$ are the specific heats of the gas and solid phases, $\lambda_{\mathrm{L}}$ is the effective axial thermal conductivity, $h_{\mathrm{f}}, h_{\mathrm{w}}$ are the heat transfer coefficient between the gas and the adsorbent and the heat transfer coefficient between the gas and the wall, and $T_{\mathrm{g}}, T_{\mathrm{s}}$, and $T_{\mathrm{w}}$ are the gas, solid, and wall temperatures.

The film heat transfer $h_{\mathrm{f}}$ is calculated from the following equation [29]:

$$
\begin{aligned}
N u_{\mathrm{g}} & =2+1,1 \operatorname{Re}^{0,6} \operatorname{Pr}^{1 / 3}, \\
N u_{\mathrm{g}} & =\frac{h_{\mathrm{f}} d_{\mathrm{p}}}{k_{\mathrm{g}}} \\
\operatorname{Re} & =\frac{\rho_{\mathrm{g}} v_{\mathrm{g}} d_{\mathrm{p}}}{\mu},
\end{aligned}
$$

$$
\operatorname{Pr}=\frac{C_{\mathrm{pg}} v_{\mathrm{g}}}{k_{\mathrm{g}}}
$$

The axial heat dispersion $\lambda_{\mathrm{L}}$ for each VOC can be estimated from the following equation [30]:

$$
\lambda_{\mathrm{L}}=D_{Z} C_{\mathrm{pg}} \rho_{\mathrm{g}}
$$

3.5. Heat Balance for the Solid Phase. The solid phase energy balance takes into account the transfer of heat over the film, axial thermal conduction, accumulation in solid phase, heat generated by the adsorption phenomenon. The energy balance equation for the bed can be expressed as in the following equation [28]:

$$
-k_{\mathrm{s}} \frac{\partial^{2} T_{\mathrm{s}}}{\partial z^{2}}+\rho_{\mathrm{p}} C_{\mathrm{ps}} \frac{\partial T_{\mathrm{s}}}{\partial t}=a_{\mathrm{s}} h_{\mathrm{f}}\left(T_{\mathrm{g}}-T_{\mathrm{s}}\right)+\sum_{i=1}^{n}\left(-\Delta H_{i}\right) \frac{\partial q_{i}}{\partial t},
$$

where $k_{\mathrm{s}}$ is the effective axial solid phase thermal conductivity, $a_{\mathrm{s}}$ expresses the ratio of the particle external surface area to volume, and $\Delta H_{i}$ is the isosteric heat of adsorption.

3.6. Numerical Solution. Aspen Adsorption enables process simulation and optimization for a wide range of industrial gas adsorption processes. It permits to choose from various geometries to complete process simulation tasks such as vacuum swing adsorption modeling. Modeling includes a wide range of kinetic models including lumped resistance, micro/macropore, and general rate. It uses a wide range of standard equilibrium models for pure and multicomponent gases. It also uses a highly configurable energy balance to account for nonisothermal behavior, conduction, heat loss, and wall effects.

Thus, the set of aforementioned partial differential equations relative to mass, heat, and momentum balances, together with the appropriate initial and boundary conditions to fully describe the adsorption process, are numerically solved by Aspen Adsorption software. The set of partial differential equations change according to assumptions considered.

3.7. VSA and TSA Simulation. After the determination of needed data to be used in simulations (adsorption isotherms and mass transfer coefficients for dichloromethane and acetone), VSA and TSA processes were designed to evaluate the feasibility of acetone and dichloromethane recovery from polluted air with activated carbon.

3.7.1. Four-Step VSA Cycle. The 4-step VSA cycle considered consists of four steps: adsorption (I), countercurrent evacuation (II), countercurrent purge (III), and cocurrent pressurization with feed (IV). A schematic diagram of a onebed VSA cycle is indicated in Figure 2(a).

In step I, a continuous feed gas (VOCs $+\mathrm{N} 2$ ) is introduced at atmospheric pressure. The desorption step of 


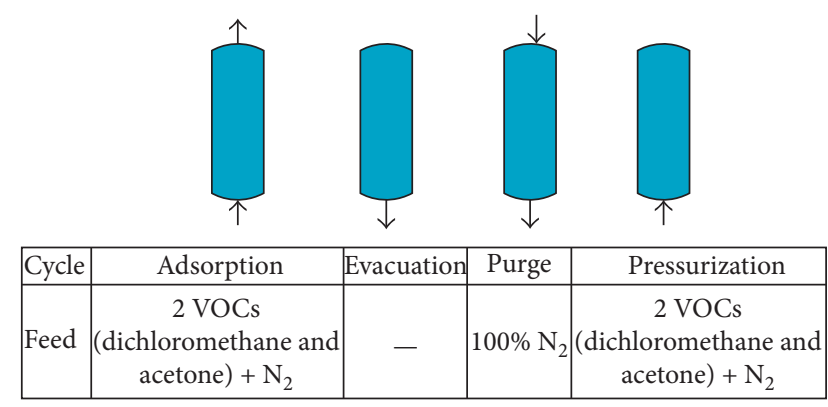

(a)

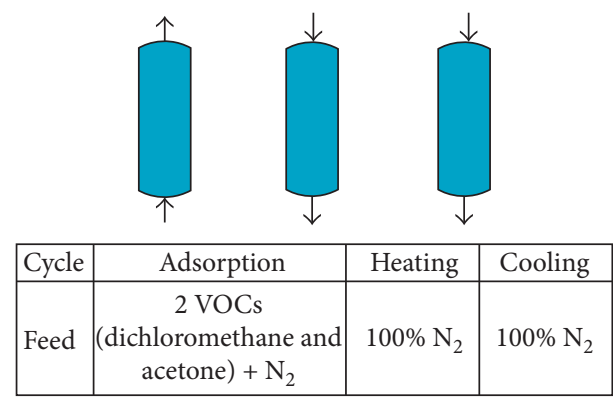

(b)

FIgURE 2: Schematic diagram and sequence of cycle steps in the operation of (a) 1-bed/4-step VSA cycle; (b) 1-bed/3-step TSA cycle for 2 VOCs removal.

VSA cycle consists of steps II and III. In the evacuation step, moles of VOCs adsorbed are removed from the bed by decreasing the bed pressure from $1 \mathrm{~atm}$ to $0.5 \mathrm{~atm}$. In the purge step, pure nitrogen is used to regenerate the bed at a pressure of $0.5 \mathrm{~atm}$. During step IV, the pressure in the column increases from $0.5 \mathrm{~atm}$ to the atmospheric pressure, the bed being pressurized by a mixture of VOCs and N2. The bed is initially filled with pure nitrogen. The duration of the adsorption step is chosen so as not to allow VOCs to breakthrough. The purge step is stopped when the entire adsorbed amount is cleared from the adsorption bed.

3.7.2. Three-Step TSA Cycle. The cycle step sequence for TSA includes adsorption (I), heating (II), and cooling (III) steps. The schematic diagram of TSA process is illustrated in Figure 2(b).

During the adsorption step, a gas mixture with $3000 \mathrm{ppm}$ dichloromethane $/ 1500 \mathrm{ppm}$ acetone is fed to the bed at $298 \mathrm{~K}$ and atmospheric pressure. During the heating step, dichloromethane and acetone are desorbed from the bed by increasing the column temperature up to $443 \mathrm{~K}$ using a hot nitrogen stream. The direct heating with hot inert gas facilitates the thermal and concentration swing for removal of the two VOCs. During the cooling step, the temperature of the bed is decreased with the aid of inert nitrogen stream at $298 \mathrm{~K}$ which comes in direct contact with the activated carbon.

3.7.3. VSA and TSA Performance. The platform of Aspen Adsorption is widely used in the industry by engineers to optimize and simulate a wide range of PSA, TSA, VSA, and other variants of these with a wide range of solid adsorbents. Aspen Adsorption can be used for adsorption process design and can reduce significantly time and cost of laboratory and pilot plant trials. This is the major benefit of simulation works. The software gives the user the freedom to configure the process to improve the plant operations in order to determine the effect of various variables on plant performance.

Using Aspen Adsorption software, VSA and TSA cycle runs are performed for a binary VOCs mixture of dichloromethane/acetone (gas inlet concentrations $3000 \mathrm{ppm} /$ $1500 \mathrm{ppm}$ ) at $298 \mathrm{~K}$ and atmospheric pressure using activated carbon.
The mathematical modeling of each step of the VSA and TSA cycles are performed by the same equations described in Section 3.

The performance of the VSA and TSA processes is analyzed through the obtained values for the recovery of dichloromethane and acetone, and this parameter is defined as the amount of the VOCs (dichloromethane and acetone) recovered during the regeneration step divided by the total amount of VOCs used during the feed step. Equations (17) and (18) are used to calculate the recovery for each VOC component at cyclic steady state conditions [31].

For the VSA process, the regeneration step includes evacuation and purge steps and the feed step comprises adsorption and pressurization steps.

$$
\operatorname{Recovery}(\%)=\frac{\left.\int_{0}^{\mathrm{II}} c_{i} v\right|_{z=L} d t+\left.\int_{0}^{\mathrm{III}} c_{i} v\right|_{z=L} d t}{\left.\int_{0}^{\mathrm{I}} c_{i} v\right|_{z=0} d t+\left.\int_{0}^{\mathrm{IV}} c_{i} v\right|_{z=0} d t} .
$$

For the TSA process, the regeneration step is the heating step and the feed step is the adsorption step.

$$
\operatorname{Recovery}(\%)=\frac{\left.\int_{0}^{\mathrm{II}} c_{i} v\right|_{z=L} d t}{\left.\int_{0}^{\mathrm{I}} c_{i} v\right|_{z=0} d t} .
$$

\section{Results and Discussion}

4.1. Adsorption Equilibrium Isotherms. Reliable adsorption equilibrium isotherms are key elements in the design of an adsorption separation process. The dynamic column breakthrough method could be used safely for obtaining singlecomponent equilibrium isotherm data. It is used herein to derive the equilibrium isotherms of dichloromethane and acetone on activated carbon. The experimental setup and analysis required for this method were previously described. The equilibrium results for these gases at atmospheric pressure and at three different temperatures are presented.

The dynamic column method of measuring singlecomponent isotherm data involves monitoring a series of breakthrough curves in a column packed with the adsorbent.

Various feed concentrations of the adsorbable component in an inert carrier are normally used in order to obtain the isotherm over a large range of concentrations. From the breakthrough curves, the adsorbed amount of VOCs for that 
particular operating conditions in equilibrium with gas phase can be deduced according to the following equation:

$$
q_{i}^{*}=\frac{Q_{\text {feed }}}{m_{\mathrm{ad}}} \int_{\mathrm{o}}^{t_{\mathrm{f}}}\left(C_{\mathrm{o}}-C(t)\right) d t,
$$

where $C_{\mathrm{o}}$ and $C(t)$ are the gas-phase concentration of VOC at the inlet and outlet of the column, respectively, $m_{\mathrm{ad}}$ is the mass of the activated carbon sample, $Q_{\text {feed }}$ is the gas flow rate, and $t_{\mathrm{f}}$ is the adsorption end time.

In the latter equation, the amounts of VOC in the interparticle and in the intraparticle voids per adsorbent mass are not considered because they are negligible in comparison with the adsorbed amount $q_{i}^{*}$.

Figures 3 and 4 show the experimental results relative to the adsorption equilibrium of pure dichloromethane and acetone on activated carbon at three temperatures $(298,313$, and $323 \mathrm{~K}$ ).

For each experimental isotherm, fitted curves obtained with the Langmuir-Freundlich model are represented. The figures show a good agreement between the values given by the two-parameter $\left(b_{i}\right.$ and $\left.q_{\mathrm{m} i}\right)$ model and the experimental data for the two VOCs at each temperature. The expressions of parameters $b_{i}$ and $q_{\mathrm{m} i}$ in function of temperature according to Equations (6) and (7) are obtained by fitting. The $\mathrm{k}_{\mathrm{i}}$ parameters for dichloromethane and acetone are given in Table 1.

4.2. Breakthrough Curves. The experimental breakthrough curves for pure solvents vapors of dichloromethane and acetone were determined at different temperatures and inlet concentrations.

Figures 5(a), 5(b), and 5(c) show a comparison between breakthrough curves obtained experimentally and by simulation using Aspen Adsorption software for dichloromethane at atmospheric pressure and for the temperatures 298,313 , and $323 \mathrm{~K}$, respectively. Inlet concentrations chosen were 500,1000, 2000, 4000, 8000, and $12000 \mathrm{ppm}$. It should be mentioned that these breakthrough curves were previously used to determine the equilibrium isotherms of dichloromethane at the different temperatures.

Figures 6(a), 6(b), and 6(c) give experimental and theoretical breakthrough curves of acetone for the same conditions.

It has to be noted that the dynamic mathematical model succeeds to predict satisfactorily the experimental data for the different conditions. This confirms the validity of the mathematical model along with the assumptions considered. The mass transfer coefficients $k_{\mathrm{LDF}}$ used in the linear driving model for dichloromethane and acetone are assessed by adjusting simulation results to experimental breakthrough curves. The kinetic parameters $\left(k_{\mathrm{LDF}}\right)$ obtained for the two VOCs for adsorption on activated carbon are given in Table 2. The $k_{\mathrm{LDF}}$ value retained corresponds to the minimum sum of squares (SS) considering the different breakthrough curves obtained for the different concentrations (similar to Equation (9)).

Figures $7(\mathrm{a}), 7(\mathrm{~b}), 7(\mathrm{c})$, and $7(\mathrm{~d})$ give breakthrough curves of binary mixtures of dichloromethane and acetone

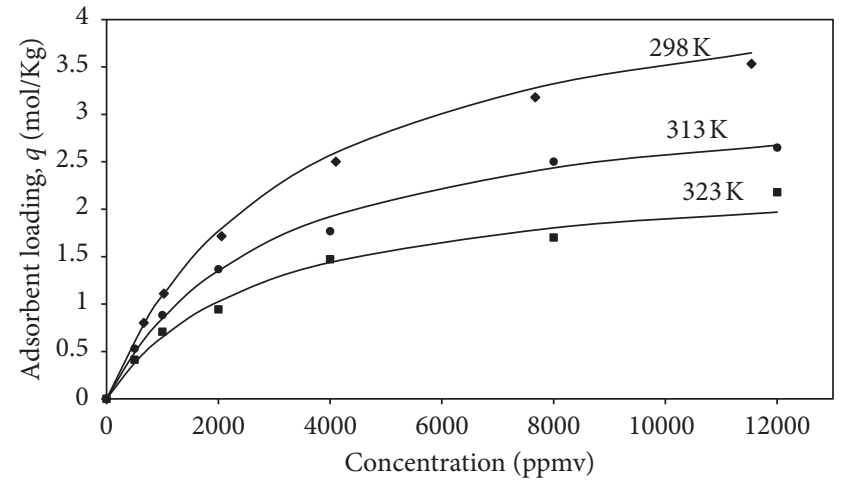

FIgURE 3: Adsorption isotherms of dichloromethane on activated carbon at 298, 313, and $323 \mathrm{~K}$ and at atmospheric pressure; symbols: experimental adsorption data; solid lines: curves fittings using extended Langmuir-Freundlich model.

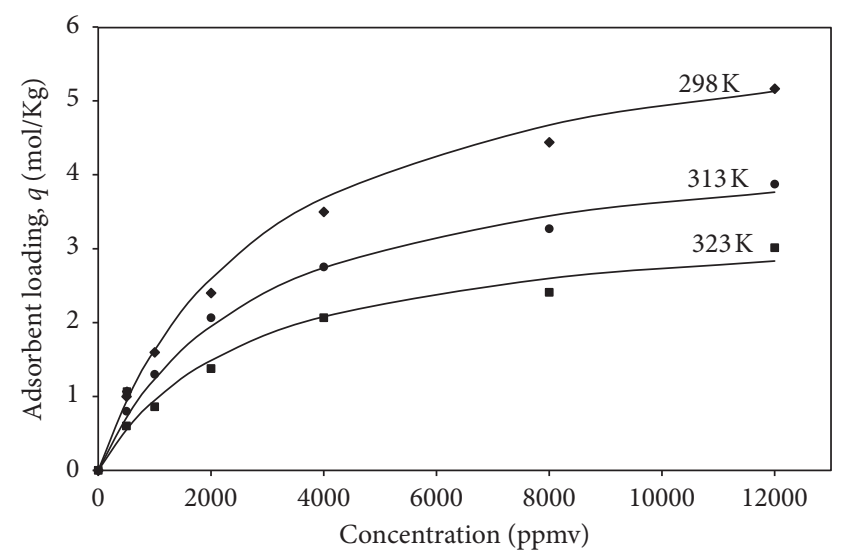

FIgURE 4: Adsorption isotherms of acetone on activated carbon at 298, 313, and $323 \mathrm{~K}$ and at atmospheric pressure; symbols: experimental adsorption data; solid lines: curves fittings using extended Langmuir-Freundlich model.

TABLE 1: Langmuir-Freundlich extended isotherm parameters for the adsorption of VOCs vapors on activated carbon.

\begin{tabular}{lcc}
\hline & Dichloromethane & Acetone \\
\hline$q_{\mathrm{m}, \mathrm{i}}(\mathrm{kmol} / \mathrm{kg})$ & 0.0051 & 0.0044 \\
$K_{1}(\mathrm{bar})$ & 0.017 & 0.014 \\
$K_{2}(\mathrm{~K})$ & 3235.5 & 4165.74 \\
$K_{3}(-)$ & 0.76 & 0.82 \\
\hline
\end{tabular}

on activated carbon for various feed compositions (3000 ppm/1500 ppm, $2000 \mathrm{ppm} / 500 \mathrm{ppm}, \quad 500 \mathrm{ppm} /$ $2000 \mathrm{ppm}$, and $750 \mathrm{ppm} / 400 \mathrm{ppm})$ at atmospheric pressure and $298 \mathrm{~K}$. Whatever the composition of the binary mixture, dichloromethane is the first compound to breakthrough. As expected, the results corroborate the ability of activated carbon to separate the dichloromethane and acetone from a nitrogen stream. For simulations, the same values of mass transfer coefficients determined previously for pure VOCs were used. Although experimental measurements can be carried out, they are laborious and time-consuming, so it is 


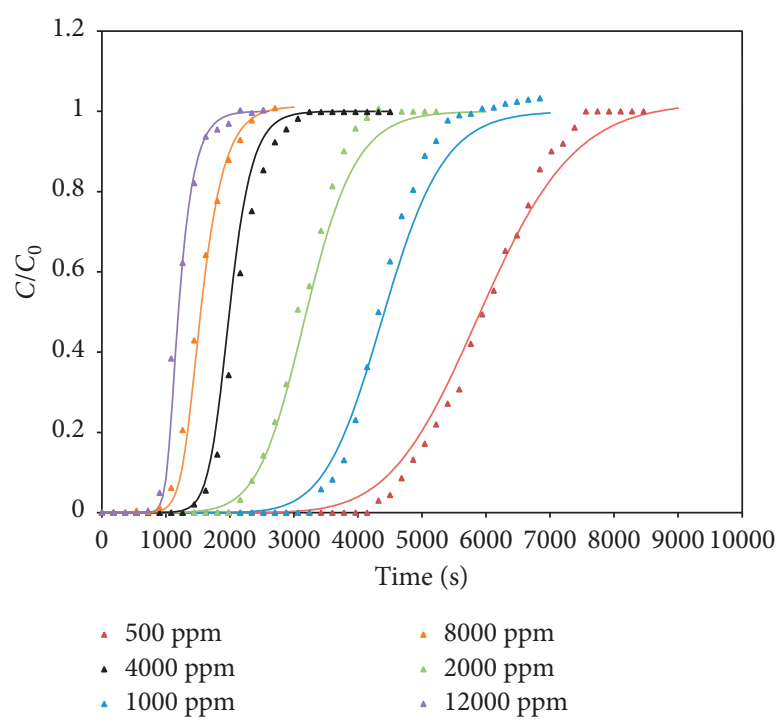

(a)

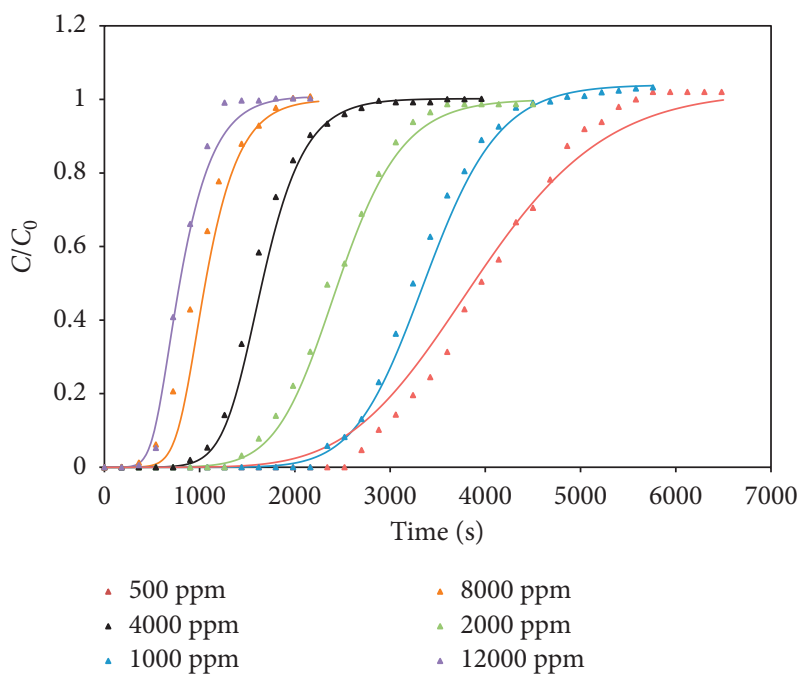

(b)

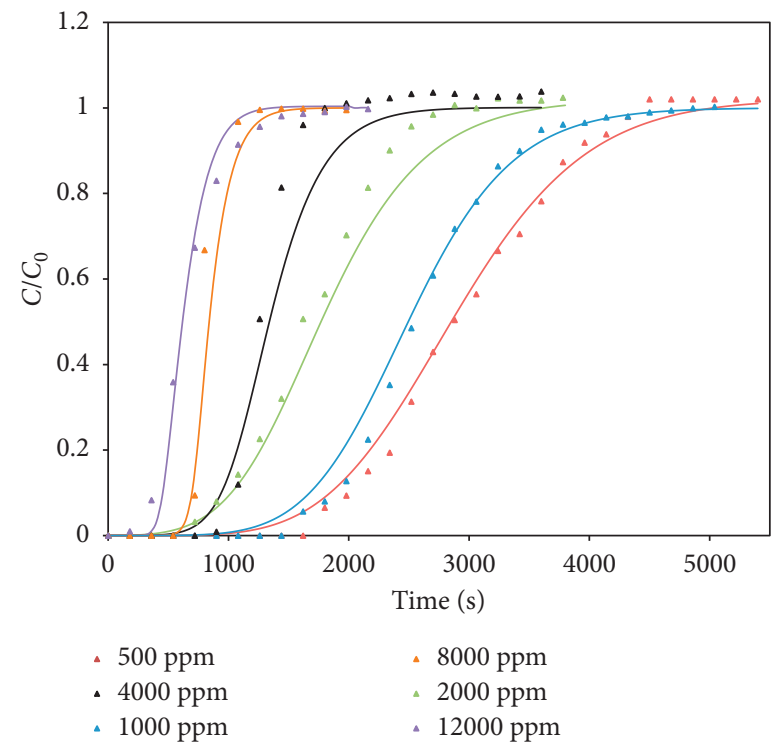

(c)

FiguRE 5: Breakthrough curves for dichloromethane adsorption on activated carbon at (a) 298 K, (b) 313 K, (c) 323 K. Symbols: experimental data. Lines: LDF model.

common practice to predict mixture isotherms from pure component isotherms. Several models for predicting mixture isotherms from pure component data have been used; the multicomponent Langmuir-Freundlich model has been used to predict mixture isotherms herein. From Figure 7, one can note that there is a good agreement between experimental and simulation results for the different binary mixtures. Thus, the dynamic mathematical model has been validated and could be used safely as a useful tool for optimization purposes of PSA or VSA processes in order to obtain highest achievable performances under the given constraints. It is worthwhile to note that the dynamic mathematical model could simulate any multicomponent gaseous mixture (more than two) provided that the adsorption equilibrium isotherms of the different components are available.
4.3. VSA Performance. The VSA performance will be assessed via process simulation which is a useful tool allowing time and money savings. The accuracy of simulations will depend, of course, on the mathematical modeling and, in particular, on the validity of assumptions considered. For the present case, the model considered permits to account for all the main mechanisms involved in the process of adsorption; it involves the mass, momentum, and energy balances that govern the process, taking into account the axial mixing and mass transfer resistances. The resulting model, which is a system of coupled algebraic and partial differential equations over time and space domains, is numerically solved by Aspen Adsorption software. As indicated previously, the performance of the VSA process will be evaluated according to product recovery. 


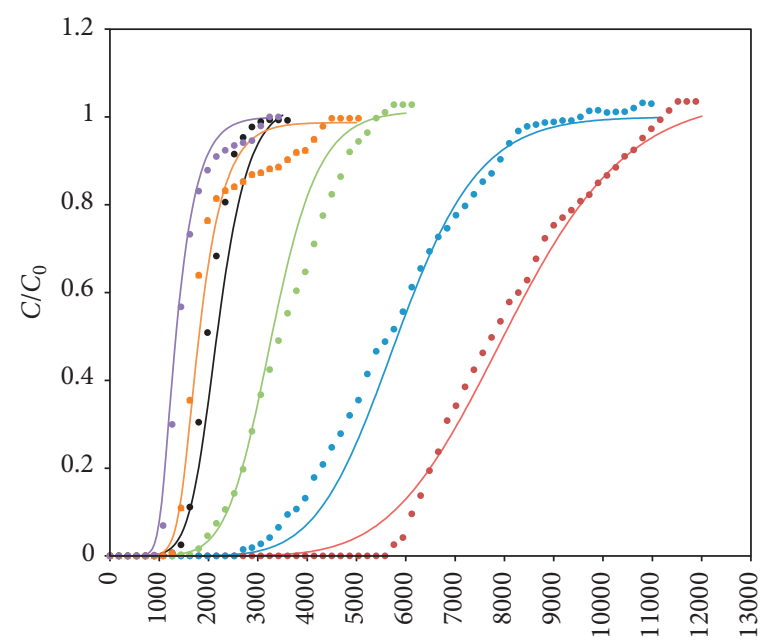

Time (s)

- $500 \mathrm{ppm}$
- $4000 \mathrm{ppm}$
- $1000 \mathrm{ppm}$
- $8000 \mathrm{ppm}$

- $2000 \mathrm{ppm}$

- $12000 \mathrm{ppm}$

(a)

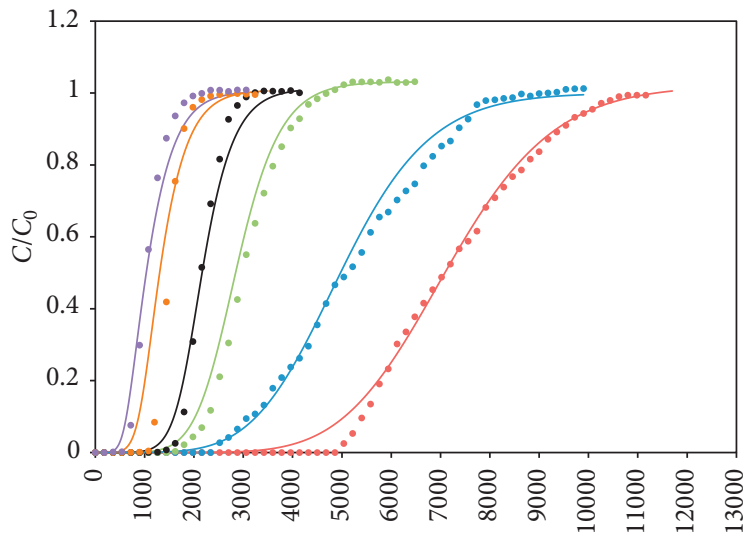

Time (s)

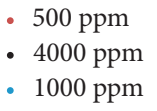

- 8000 ppm

- $2000 \mathrm{ppm}$

- $12000 \mathrm{ppm}$

(b)

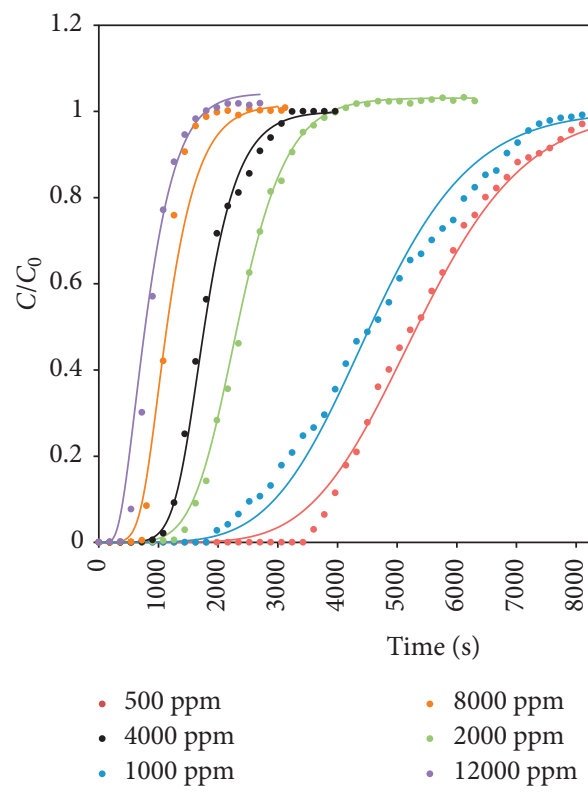

(c)

Figure 6: Breakthrough curves for acetone adsorption on activated carbon at (a) $298 \mathrm{~K}$, (b) $313 \mathrm{~K}$, (c) $323 \mathrm{~K}$. Symbols: experimental data. Lines: LDF model.

TABLE 2: Mass transfer coefficients $k_{\mathrm{LDF}}$ for VOCs vapors for dichloromethane and acetone.

\begin{tabular}{lc}
\hline VOC & $k_{\mathrm{LDF}}\left(\mathrm{s}^{-1}\right)$ \\
\hline Dichloromethane & 0.008 \\
Acetone & 0.01 \\
\hline
\end{tabular}

The aim of simulations is to test the feasibility of the VSA cycle in removing and recovering dichloromethane and acetone from polluted air with activated carbon and find the optimal operational parameters in order to provide useful information for future industrial design and application. The simulation results obtained for a one-bed VSA process are represented in this section. The conditions of simulations of the VSA cycle are summarized in Table 3.

The following simulation results are relative to a feed whose composition is 3000 and 1500 ppm for dichloromethane and acetone, respectively. The corresponding simulation results are obtained for the cyclic steady state which is attained after nearly 10 cycles. Figure 8 shows the pressure history at one end of the adsorption column (closed end for pressurization and evacuation steps) during one cycle at steady state.

The simulated axial profiles of the adsorbed amount of dichloromethane and acetone at the end of different steps of 


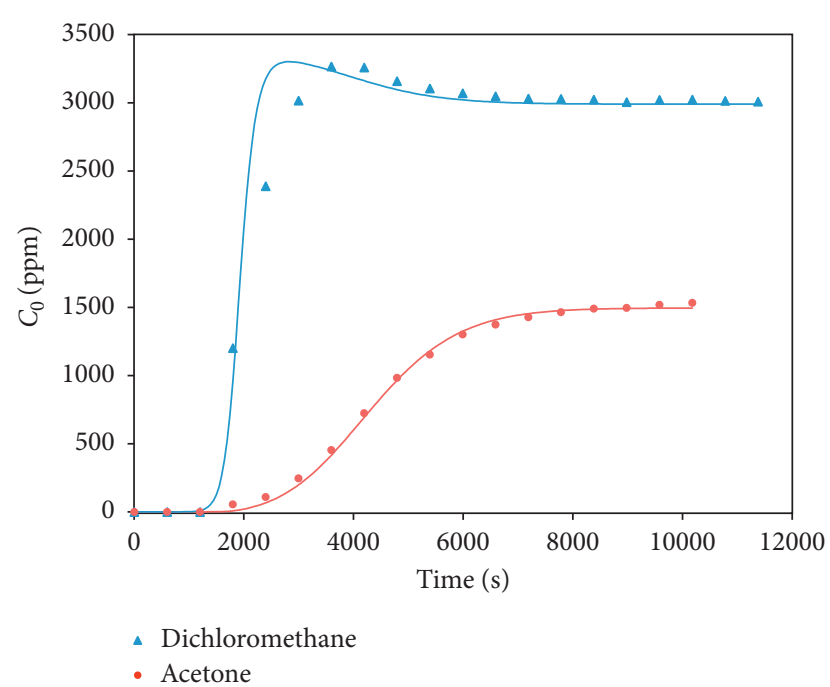

(a)

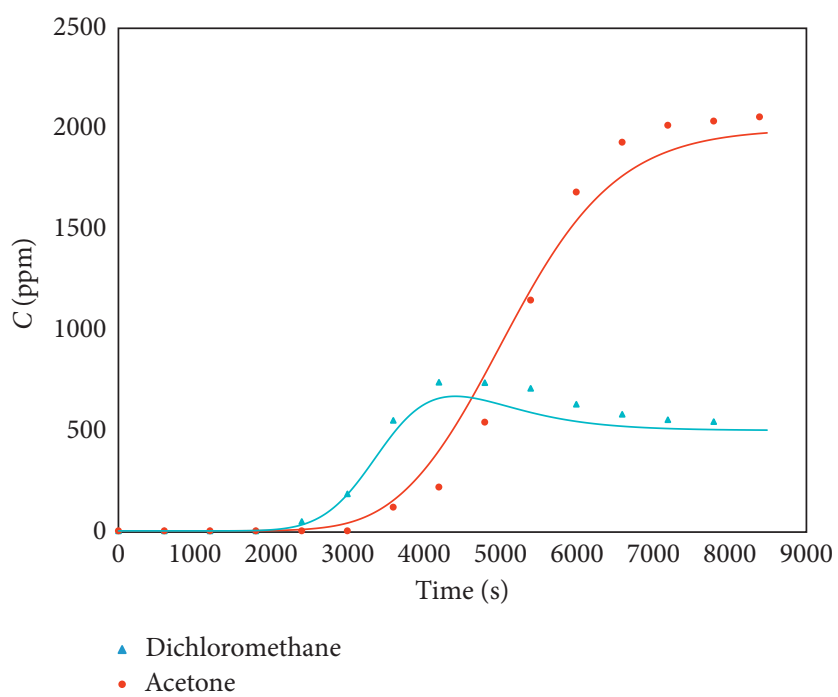

(c)

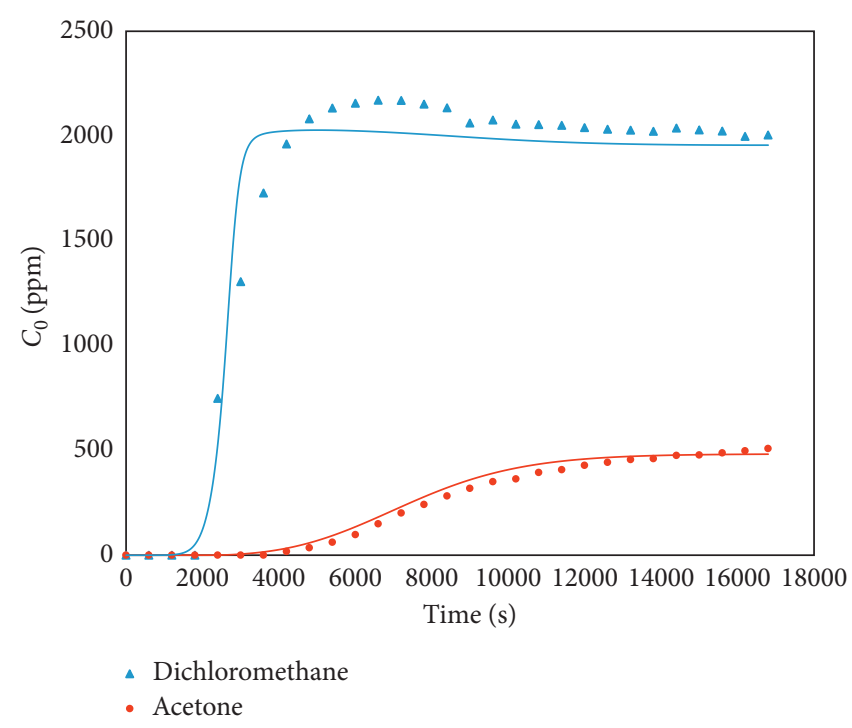

(b)

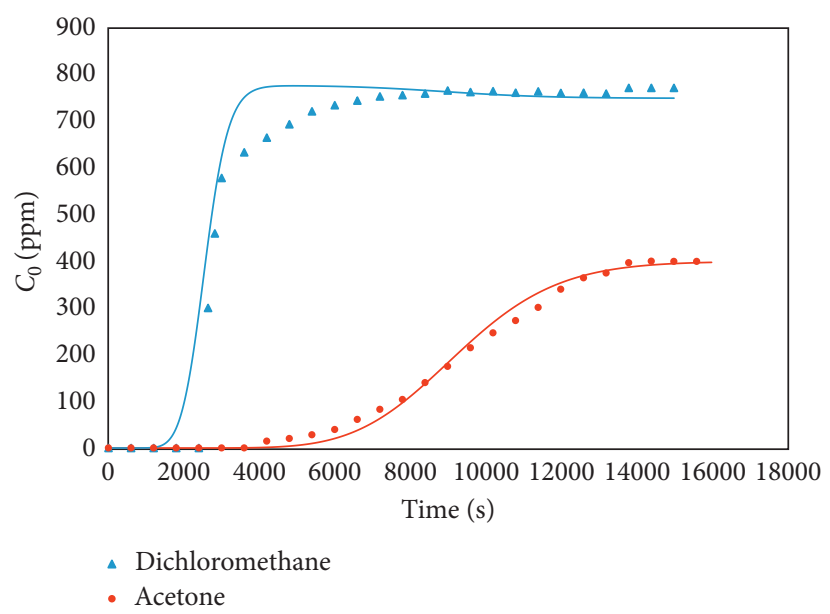

(d)

FiguRE 7: Breakthrough curves of mixtures of dichloromethane and acetone for different compositions: (a) 3000 ppm/1500 ppm, (b) $2000 \mathrm{ppm} / 500 \mathrm{ppm}$, (c) $500 \mathrm{ppm} / 2000 \mathrm{ppm}$, and (d) $750 \mathrm{ppm} / 400 \mathrm{ppm}$ on activated carbon, at $298 \mathrm{~K}$ and atmospheric pressure. Symbols: experimental data. Lines: LDF model.

the cycle at steady state are given in Figure 9. One can note that despite the decrease of pressure from 1.0 (pressure prevailing at the end of the adsorption step) to $0.5 \mathrm{~atm}$ (value of pressure at the end of the evacuation step), the axial profiles of the adsorbed amount of dichloromethane and acetone have decreased slightly. In fact, mass transfer between solid and gas phases which is controlled by intraparticle diffusion, being very slow, does not permit the two phases to be in equilibrium given the rapid change in pressure.

On the contrary, the small amount of dichloromethane and acetone desorbed during the evacuation step due to the pressure decrease results in a notable increase in the concentration in the gas phase at the end of this step as can be seen in Figure 10. The concentration of dichloromethane and acetone has nearly doubled in the saturated zone of the bed, passing from 3000 to $6000 \mathrm{ppm}$ for dichloromethane and from 1500 to 3000 for acetone. If the equilibrium model was used instead of the linear driving force model to account for intraparticle mass transfer resistances, the adsorbed amount of dichloromethane obtained at the end of the evacuation step would have been much lower.

The corresponding axial temperature profiles at the end of adsorption, evacuation, and purge steps are shown in Figure 11. Once again, because of the small amount of VOCs desorbed during the evacuation step, the decrease in temperature due to desorption during this step is very slight. However, the difference in temperature between the two ends of the bed could reach a value of $10^{\circ} \mathrm{C}$ (during the purge step). As can be seen in Figures 3 and 4 giving the adsorption 
TABLE 3: Adsorbent and bed characteristics and operating conditions used in the Aspen Adsorption simulations.

\begin{tabular}{|c|c|}
\hline Parameter & Value \\
\hline Number of adsorbent bed & 1 \\
\hline VOC mixture & Dichloromethane/acetone \\
\hline Concentration (ppm) & $3000 / 1500$ \\
\hline Bed height $(\mathrm{m})$ & 1 \\
\hline Bed diameter (m) & 0.2 \\
\hline Packing density $\left(\mathrm{kg} \cdot \mathrm{m}^{-3}\right)$ & 250 \\
\hline Particle diameter (mm) & 1 \\
\hline Interparticle voidage, $\varepsilon$ & 0.4 \\
\hline Void of pellets, $\varepsilon_{\mathrm{p}}$ & 0.36 \\
\hline$\Delta H_{\text {dichloromethane }}(\mathrm{kJ} / \mathrm{mol})$ & -40 \\
\hline$\Delta H_{\text {acetone }}(\mathrm{kJ} / \mathrm{mol})$ & -50 \\
\hline$D_{\mathrm{z}}\left(\mathrm{m}^{2} \cdot \mathrm{s}^{-1}\right)$ & $1.8310^{-3}$ \\
\hline$h_{\mathrm{f}}\left(\mathrm{W} \cdot \mathrm{m}^{-2} \cdot \mathrm{K}^{-1}\right)$ & 56 \\
\hline$\lambda_{\mathrm{L}}\left(\mathrm{W} \cdot \mathrm{m}^{-2} \cdot \mathrm{K}^{-1}\right)$ & 48 \\
\hline Feed flow rate $(\mathrm{mol} / \mathrm{min})$ & 20 \\
\hline Purge flow rate (mol/min) & 12 \\
\hline$T_{\text {ads }}(\mathrm{K})$ & 298 \\
\hline \multicolumn{2}{|l|}{ VSA cycle } \\
\hline Adsorption pressure (atm) & 1 \\
\hline Desorption pressure (atm) & 0.5 \\
\hline$t_{\mathrm{ad}}(\mathrm{s})$ & 9000 \\
\hline$t_{\text {evac }}(\mathrm{s})$ & 60 \\
\hline$t_{\mathrm{pg}}(\mathrm{s})$ & 40000 \\
\hline$t_{\mathrm{PR}}(\mathrm{s})$ & 80 \\
\hline Cycle time (s) & 49140 \\
\hline \multicolumn{2}{|l|}{ TSA cycle } \\
\hline Adsorption pressure (atm) & 1 \\
\hline$T_{\mathrm{des}}(\mathrm{K})$ & 443 \\
\hline$t_{\mathrm{ad}}(\mathrm{s})$ & 9000 \\
\hline$t_{\text {heat }}(\mathrm{s})$ & 7600 \\
\hline$t_{\text {cool }}(\mathrm{s})$ & 5500 \\
\hline Cycle time (s) & 22100 \\
\hline
\end{tabular}

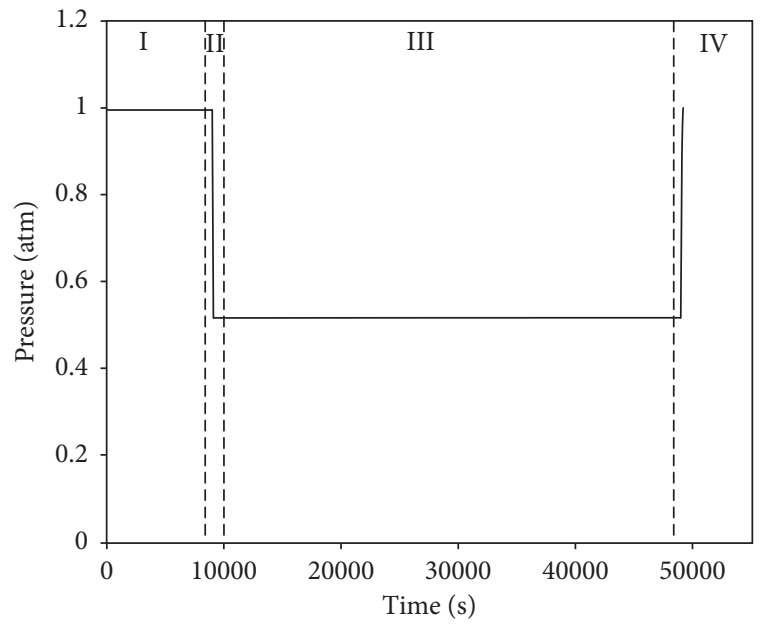

FIGURE 8: Pressure history of the adsorption column during one cycle for a VOCs mixture of dichloromethane/acetone (3000 ppm/1500 ppm).

equilibrium isotherms of dichloromethane and acetone for different temperatures, a deviation of $10^{\circ} \mathrm{C}$ can have a significant effect on the adsorbed amount of dichloromethane and acetone. This demonstrates that incorporating energy

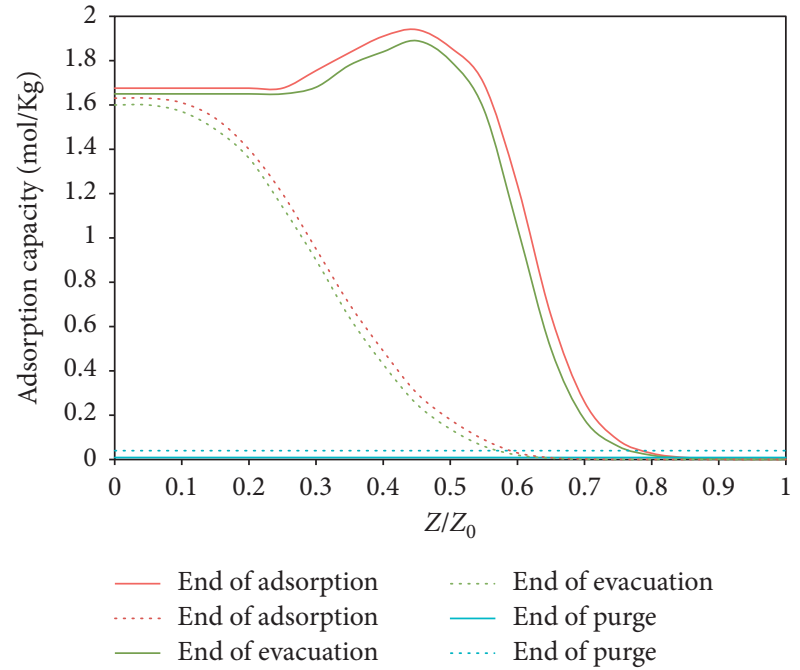

FIgURE 9: Simulated axial profiles of the adsorbed amount of dichloromethane and acetone at the end of different steps of the cycle at steady state. Solid lines: dichloromethane and dotted lines: acetone.

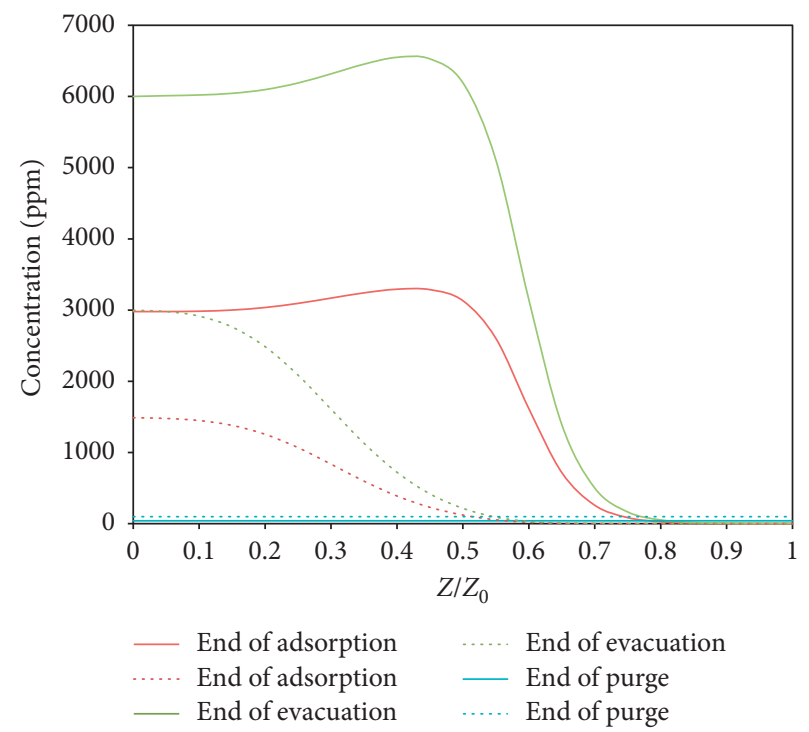

Figure 10: Simulated axial concentration profiles of dichloromethane and acetone at the end of different steps of the cycle at steady state. Solid lines: dichloromethane and dotted lines: acetone.

balances in modeling is a judicious choice, and hence, simulation results of models dealing with VOCs adsorption assuming isothermal conditions should be considered with a great precaution.

Figure 12 gives histories of dichloromethane and acetone concentration at the bed exit during evacuation and purge steps at cyclic steady state. The concentrations of the two VOCs diminish gradually from the highest values attained at the end of the evacuation step until values approaching zero at the end of purge step. The desorbed VOCs in the outlet stream could be pumped to a condenser where they could be separated from $\mathrm{N}_{2}$ and recovered as a liquid. This process involves cooling the outlet stream to a temperature below the dew point of each VOC. 


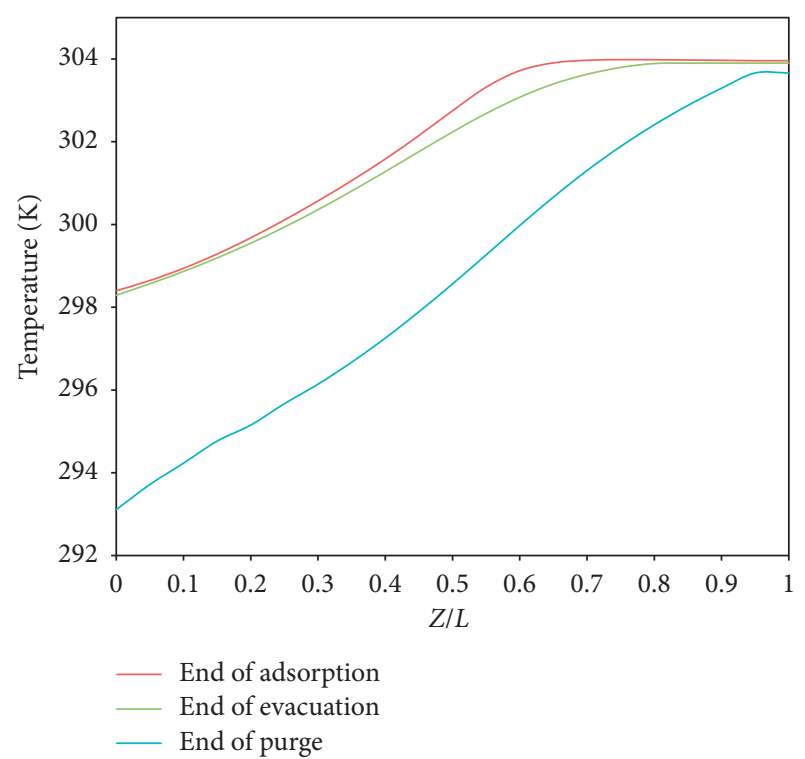

Figure 11: Axial Temperature profiles at the end of different steps of the cycle at steady state.

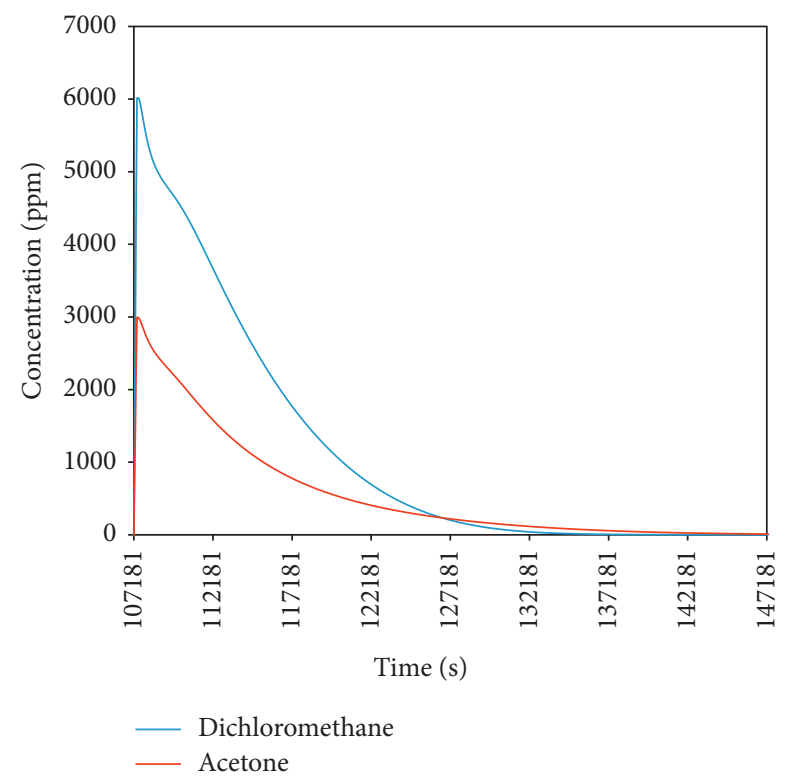

FIGURE 12: Histories of dichloromethane and acetone concentration at the bed exit during evacuation and purge steps at cyclic steady state.

The improvement of the performance of the VSA cycle is achieved through the optimization of the operating parameters, one among these parameters is the adsorption step time. Figure 13 gives the variation of recovery of dichloromethane and acetone with the adsorption step duration $t_{\mathrm{ad}}$. All the operating parameters of the VSA cycle are kept unchanged except for $t_{a d}$. Detailed operating conditions and cycle parameters are given in Table 3. According to simulation results, it is clear that the VSA unit can recover completely the two VOCs (100\% of dichloromethane and acetone) for $t_{\text {ad }}$ equal to $9000 \mathrm{~s}$. For this value

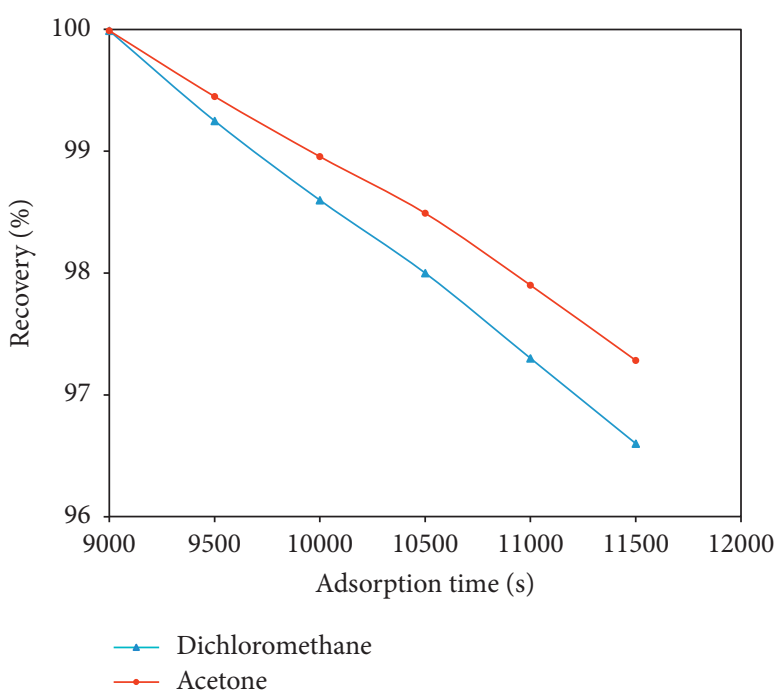

FIGURE 13: Recovery of dichloromethane and acetone with the adsorption step duration.

of $t_{\mathrm{ad}}$, only pure $\mathrm{N}_{2}$ exits the bed, the two VOCs are totally retained. Adsorbed VOCs are then totally desorbed during the subsequent steps (evacuation and purge), thus permitting to get a recovery of $100 \%$. The recovery of the two VOCs decreases then gradually when $t_{\text {ad }}$ increases. This can be explained by the fact that the two VOCs break through upon saturation of the bed, if $t_{\mathrm{ad}}$ exceeds $9000 \mathrm{~s}$, as shown in Figure 14 giving the change with the adsorption step time of the maximum concentration of the two VOCs attained at the outlet of the column at cyclic steady state. The amount of VOCs exiting the bed during the adsorption step constitutes a loss and causes a decrease in recovery. The adsorption step duration should be determined precisely so as not to affect the recovery and alter the quality of air being purified due to the breakthrough of VOCs.

The vacuum pressure is also a major operating parameter in the VSA process and affects significantly its performance. It has to be noted that more than $70 \%$ of the power consumption of the VSA cycle is attributed to the vacuum pump [32]. Thus, the evacuation pressure has a tremendous effect on the energy performance of the process, and its choice should be optimized so as to lower the power consumption of the system. If the vacuum pressure chosen is too low, the power consumption becomes too high. On the contrary, if the vacuum pressure selected is not low enough, the duration of the purge step will be too long. This depends of course on the shape of the adsorption isotherm. The greater the slope of the adsorption isotherm, the greater the effect of the decrease in pressure on the process performance.

Figure 15 shows the variation of purge step time with vacuum pressure. For the different simulations, the $\mathrm{N}_{2}$ molar flow rate is maintained constant $(12 \mathrm{~mol} / \mathrm{mn})$ and the duration of the purge step is chosen so as to obtain a recovery of $100 \%$ for dichloromethane and acetone. The other parameters are maintained unchanged (as indicated in Table 3). For $P_{\text {des }}=1 \mathrm{~atm}$, the VSA cycle is only composed of two steps at the same pressure, adsorption, and purge, and there is no 


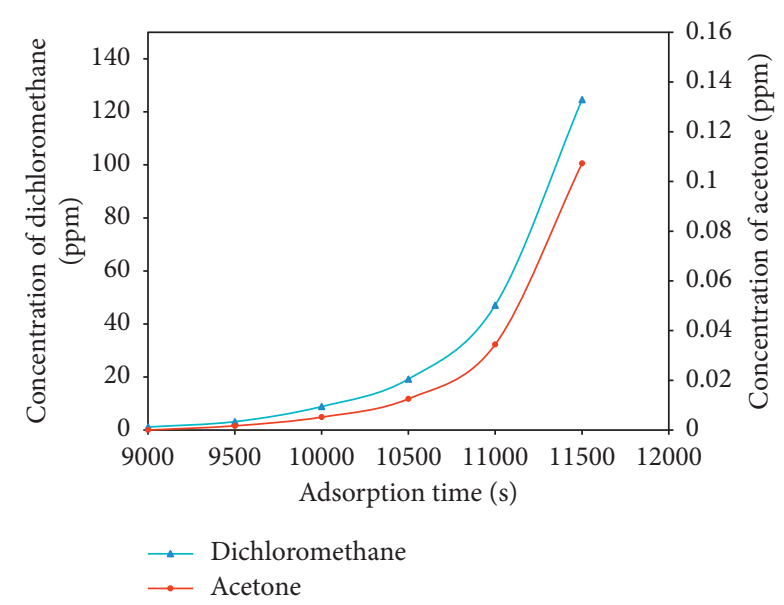

Figure 14: Maximum concentration of dichloromethane and acetone at the end the adsorption step for different.

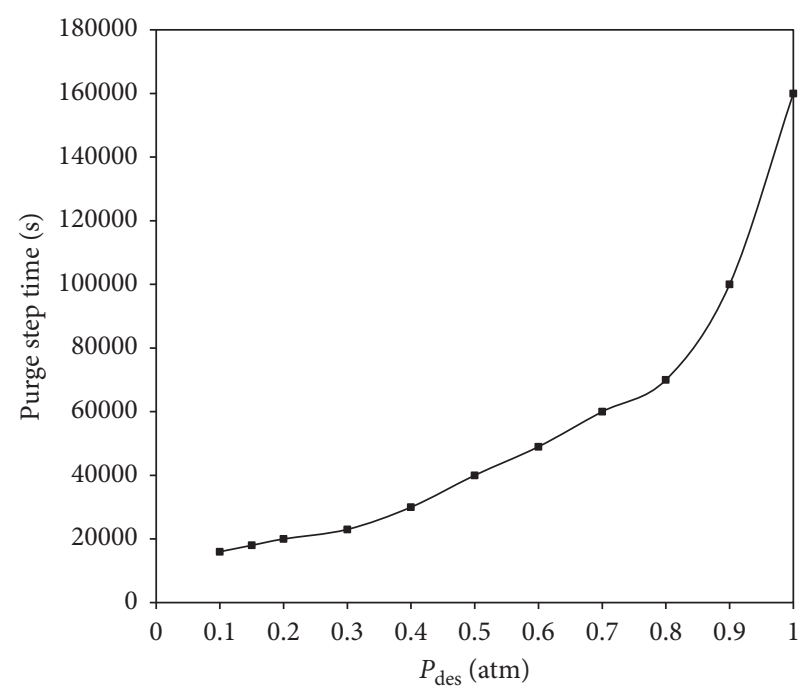

FIGURE 15: Variation of purge step time with vacuum pressure for mixtures dichloromethane/acetone vapor at $3000 \mathrm{ppm} / 1500 \mathrm{ppm}$ exposure concentration.

pressure change. For the case being studied, decreasing $P_{\text {des }}$ leads to a substantial decrease in the duration of the step. In fact, the purge step time is divided by 10 when the vacuum pressure goes from 1 to $0.1 \mathrm{~atm}$. For $P_{\text {des }}=0.1 \mathrm{~atm}, 16000 \mathrm{~s}$ are sufficient to regenerate the bed while $160000 \mathrm{~s}$ are necessary for $P_{\mathrm{des}}=1 \mathrm{~atm}$. As expected, the vacuum level has an appreciable effect on the VSA performance. However, the choice of the vacuum pressure has an impact on energy consumption depending on the value of the vacuum pressure and also on the duration of the purge step. The higher the vacuum pressure, the shorter the duration of the purge step but the higher the energy consumption. A compromise must be found between the energy consumption and the duration of the step. The total amount of gas used to purge the adsorber which is proportional to the duration of the purge step, given that its molar flow rate at the bed inlet is constant, increases with vacuum pressure. The amount of $\mathrm{N}_{2}$ consumed for desorbing the bed increases notably with the vacuum pressure, it varies from 3 to $32 \mathrm{kmol}$ when vacuum pressure increases from 0.1 to $1 \mathrm{~atm}$, respectively. The vacuum pressure should be carefully chosen in order to both reduce the energy consumption and shorten the purge step duration.

4.4. TSA Performance. This section deals with the TSA process for the recovery of the same VOCs. The detailed cycle conditions are presented in Table 3. Simulations carried out show that cyclic steady state of the process is reached after approximately 12 cycles.

Figure 16 shows the dichloromethane and acetone concentration history at the column outlet during the heating step. The evolution with time of gas temperature at the exit of the bed for one cycle at cyclic steady state is given in Figure 17.

As can be seen from Figure 16, the increase of the bed temperature due to heating results in a more rapid regeneration of the bed in comparison with the VSA process. In the case being studied, it appears clearly that an increase in temperature during the regeneration step is more efficient than a decrease of pressure. Compared to the concentrations obtained for a VSA process, much higher concentrations of dichloromethane and acetone are obtained (approximately 32000 (6000 for VSA) and 12000 (3000 for VSA) ppm resp.). This shows that the desorbed amount of the two VOCs is more sensitive to a variation of temperature than to a variation of pressure.

During the heating step, the concentration waves of the 2 VOCs and temperature wave propagate together through the column. In terms of desorption, the higher temperature is, the weaker the van der Waals forces between VOCs and the surface of activated carbon becomes, which leads to an increasing regeneration at high desorption temperature. Since desorption temperature is the most important factor concerning the performance of the regeneration step, the effects of this operating parameter on recovery are investigated for the TSA process. Figure 18 shows the variation of the heating step duration versus desorption temperature. For the various simulations, the hot nitrogen stream used in the heating step is maintained constant $(12 \mathrm{~mol} / \mathrm{min})$ and the necessary duration of this step is optimized to totally recover the 2 VOCs (100\% recovery). Also, all the operating parameters of the 3-step TSA cycle (as indicated in Table 3) are kept unchanged except for $T_{\text {des }}$ and $t_{\text {heat }}$.

When desorption temperature increases from 403 to $443 \mathrm{~K}$, the purge duration decreases from 8600 to $7600 \mathrm{~s}$. The corresponding N2 amount consumed for the regeneration of the column decreases slightly from 1.72 to $1.52 \mathrm{kmol}$. These values are much lower than those obtained for the VSA process.

The simulation results obtained for the VSA and TSA processes show that it is possible to achieve high dichloromethane and acetone recovery (a value of 100\% for the 2 VOCs could be obtained).

For the VSA process, it has been shown that the duration of the regeneration step for a $100 \%$ recovery of the two 


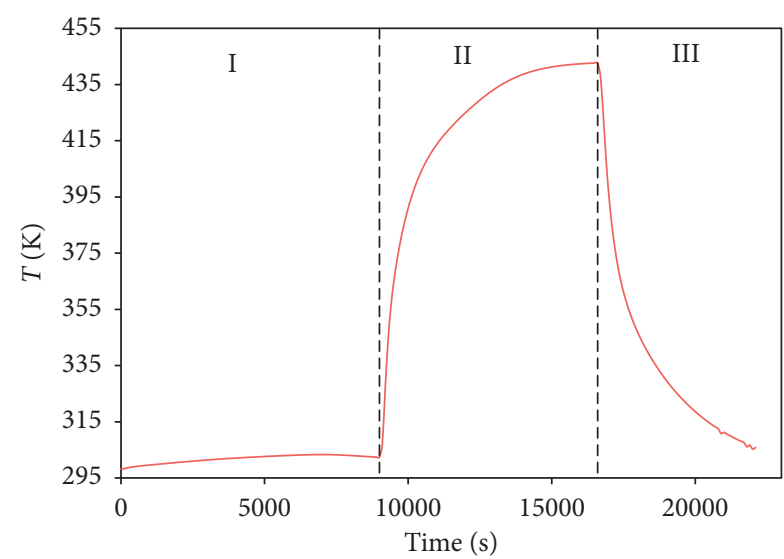

FIGURE 16: Gas temperature history along the bed during one cycle.

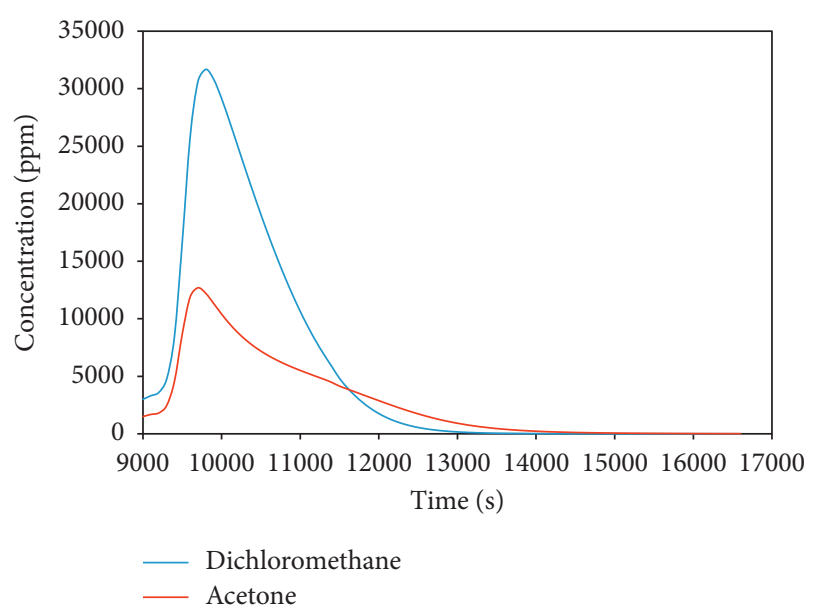

FIGURE 17: Concentration of dichloromethane and acetone profiles at the column outlet during the heating step.

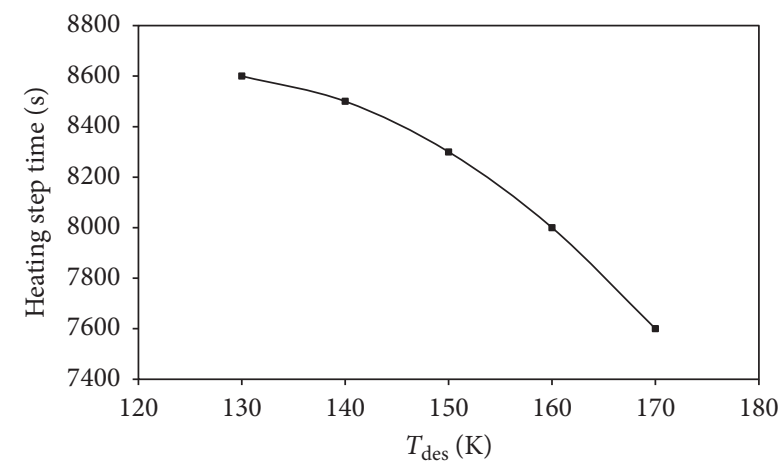

Figure 18: Variations of heat duration step versus desorption temperature.

VOCs varies from 20000 to $160000 \mathrm{~s}$ for desorption pressures varying from 0.1 to $1 \mathrm{~atm}$ (Figure 15). For the TSA process, the regeneration step durations vary from 8600 to $7600 \mathrm{~s}$ when the desorption temperature changes from 403 to $443 \mathrm{~K}$ at a pressure of $1 \mathrm{~atm}$. Thus, there is a substantial decrease in the total duration of the TSA cycle compared to the VSA cycle. Regeneration by hot nitrogen stream seems to be more efficient than regeneration by reducing pressure.

\section{Conclusion}

Volatile organic compounds are air pollutants that should be removed to avoid serious effects on human health and environment. A particular interest has been given to the recovery of dichloromethane and acetone used as solvents in oil sands process for extraction of bitumen. Experimental adsorption isotherms of the two VOCs are determined at three different temperatures by the dynamic column breakthrough method. The developed simulation model using Aspen Adsorption software has been used successfully to predict the experimental breakthrough curves for pure VOCs and different binary mixtures for various conditions. The mass transfer coefficients $k_{\mathrm{LDF}}$ used in the linear driving model for dichloromethane and acetone are assessed by adjusting simulation results to experimental breakthrough curves. The validated simulation model has been used for optimizing vacuum and temperature swing adsorption processes so as to achieve the highest performances. Emphasis has been given to the effect of many operating parameters, that is, the adsorption step duration, the vacuum pressure, and the desorption temperature, on the recovery of dichloromethane and acetone. It has been shown that a recovery of $100 \%$ of the two VOCs could be attained. However, the adsorption step duration should be determined precisely so as not to affect the recovery and alter the quality of air being purified due to the breakthrough of VOCs. The vacuum pressure and the desorption temperature should be carefully chosen in order to both reduce the energy consumption and shorten the purge step duration. It has to be noted that regeneration by hot nitrogen stream is more efficient than regeneration by reducing pressure.

\section{Nomenclature}

$a_{\mathrm{s}}: \quad$ Express the ratio of the particle external surface area to volume, $\mathrm{m}^{2} \cdot \mathrm{m}^{-3}$

$B: \quad$ Langmuir-Freundlich equation parameter

C: $\quad$ Concentration of the VOC, $\mathrm{mol} \cdot \mathrm{m}^{-3}$

$C_{\mathrm{ps}}: \quad$ Heat capacity of the adsorbent, $\mathrm{J} \cdot \mathrm{kg}^{-1} \cdot \mathrm{K}^{-1}$

$C_{\mathrm{O}}$ : Initial inlet concentration, $\mathrm{ppm}$

$C_{\mathrm{pg}}: \quad$ Gas heat capacity, $\mathrm{J} \cdot \mathrm{kg}^{-1} \cdot \mathrm{K}^{-1}$

$D_{\mathrm{p}}$ : $\quad$ Particle diameter, $\mathrm{m}$

$d_{\text {int }}: \quad$ Column internal diameter, $m$

$D_{\mathrm{e}}: \quad \quad$ Effective diffusivity of the VOC, $\mathrm{m}^{2} \cdot \mathrm{s}^{-1}$

$D_{z}: \quad$ Axial dispersion coefficient, $\mathrm{m}^{2} \cdot \mathrm{s}^{-1}$

$k_{1}, k_{2}, k_{3}$ : Langmuir-Freundlich equation parameter

$k_{\mathrm{LDF}}: \quad$ Mass transfer coefficient, $\mathrm{s}^{-1}$

$K_{\mathrm{g}}: \quad$ Gas thermal conductivity, $\mathrm{W} \cdot \mathrm{m}^{-1} \cdot \mathrm{K}^{-1}$

$k_{\mathrm{s}}$ : $\quad$ Effective axial solid phase thermal conductivity, $\mathrm{W} \cdot \mathrm{m}^{-2} \cdot \mathrm{K}^{-1}$

$h_{\mathrm{f}}: \quad$ Film heat transfer, $\mathrm{W} \cdot \mathrm{m}^{-2} \cdot \mathrm{K}^{-1}$

L: $\quad$ Bed height, $m$

$m_{\mathrm{ad}}$ : $\quad$ Mass of the sample of activated carbon in the bed, $g$

Q: $\quad$ Average adsorbed concentration, $\mathrm{mol} \cdot \mathrm{kg}^{-1}$ 


\begin{tabular}{|c|c|}
\hline$q *:$ & $\begin{array}{l}\text { Equilibrium adsorption concentration, } \\
\mathrm{mol} \cdot \mathrm{kg}^{-1}\end{array}$ \\
\hline$Q_{\mathrm{m}}:$ & Adsorption capacity of the amount, $\mathrm{mol} \cdot \mathrm{kg}^{-1}$ \\
\hline$R_{\mathrm{p}}:$ & Particle radius, $\mathrm{m}$ \\
\hline$P:$ & Pressure, $\mathrm{Pa}$ \\
\hline$P_{\mathrm{ad}}:$ & Feed pressure in adsorption step, atm \\
\hline$P_{\text {des: }}:$ & $\begin{array}{l}\text { Vacuum pressure in evacuation and purge } \\
\text { step, atm }\end{array}$ \\
\hline$\dot{Q}_{\text {feed }}:$ & Molar flow, $\mathrm{mol} \cdot \mathrm{min}^{-1}$ \\
\hline$\dot{Q}_{\mathrm{pg}}:$ & Molar flow of purge step, $\mathrm{mol} \cdot \mathrm{min}^{-1}$ \\
\hline$t:{ }^{\text {Po }}$ & Time, s \\
\hline$t_{\mathrm{f}}:$ & Adsorption end time, min \\
\hline$t_{\mathrm{ad}}:$ & Adsorption step time, $s$ \\
\hline$t_{\text {cool }}:$ & Cool step time, $s$ \\
\hline$t_{\text {evac: }}:$ & Evacuation step time, $s$ \\
\hline$t_{\text {heat }}:$ & Heat step time, $s$ \\
\hline$t_{\mathrm{pg}}:$ & Purge step time, s \\
\hline$t_{\mathrm{PR}}:$ & Pressurization step time, $s$ \\
\hline$T:$ & Temperature, $\mathrm{K}$ \\
\hline$T_{\mathrm{ad}}:$ & Adsorption temperature, $\mathrm{K}$ \\
\hline$T_{\text {des }}:$ & Desorption temperature, $\mathrm{K}$ \\
\hline$Z:$ & Axial co-ordinate along the bed, $\mathrm{m}$ \\
\hline$v_{\mathrm{g}}:$ & Interstitial velocity, $\mathrm{m} \cdot \mathrm{s}^{-1}$ \\
\hline$a_{\mathrm{s}}:$ & $\begin{array}{l}\text { Express the ratio of the particle external } \\
\text { surface area to volume, } \mathrm{m}^{2} \cdot \mathrm{m}^{-3}\end{array}$ \\
\hline$\rho_{\mathrm{g}}:$ & Gas density, $\mathrm{kg} \cdot \mathrm{m}^{-3}$ \\
\hline$\rho_{\mathrm{p}}$ & Particle density, $\mathrm{kg} \cdot \mathrm{m}^{-3}$ \\
\hline$\varepsilon:$ & Void fraction \\
\hline$\varepsilon_{\mathrm{p}}:$ & Void of pellets \\
\hline$\mu:$ & Dynamic viscosity, Pa.s \\
\hline$\lambda_{\mathrm{L}}:$ & Axial heat dispersion, $\mathrm{W} \cdot \mathrm{m}^{-2} \cdot \mathrm{K}^{-1}$ \\
\hline$\Delta H:$ & Isosteric heat of adsorption, $\mathrm{J} \cdot \mathrm{mol}^{-1}$ \\
\hline I: & Component \\
\hline $\mathrm{J}:$ & Component \\
\hline III, VI: & Step numbers. \\
\hline
\end{tabular}

\section{Data Availability}

The data used to support the findings of this study are included within the article.

\section{Conflicts of Interest}

The authors declare that they have no conflicts of interest.

\section{References}

[1] F. I. Khan and A. K. Ghosal, "Removal of volatile organic compounds from polluted air," Journal of Loss Prevention in the Process Industries, vol. 13, no. 6, pp. 527-45, 2000.

[2] I. K. Shah, P. Pré, and B. J. Alappat, "Effect of thermal regeneration of spent activated carbon on volatile organic compound adsorption performances," Journal of the Taiwan Institute of Chemical Engineers, vol. 45, no. 4, pp. 1733-1738, 2014.

[3] J. Read, D. Whiteoak, and S. Bitumen, The Shell Bitumen Handbook, Thomas Telford Publishers, London, UK, 5th edition, 2003.

[4] J. Sundell, "On the history of indoor air quality and health," Indoor Air, vol. 14, no. s7, pp. 51-58, 2004.
[5] T. Dobre, O. C. Pârvulescu, A. Jacquemet, and V. A. Ion, "Adsorption and thermal desorption of volatile organic compounds in a fixed bed-experimental and modelling," Chemical Engineering Communications, vol. 203, no. 12, pp. 1554-1561, 2016.

[6] G. S. Cooper, C. S. Scott, and A. S. Bale, "Insights from epidemiology into dichloromethane and cancer risk," International Journal of Environmental Research and Public Health, vol. 8, no. 8, pp. 3380-3398, 2011.

[7] P. M. Bos, M. J. Zeilmaker, and J. C. van Eijkeren, "Application of physiologically based pharmacokinetic modeling in setting acute exposure guideline levels for methylene chloride," Toxicological Sciences, vol. 91, no. 2, pp. 576-585, 2006.

[8] F. Zeinali, A. A. Ghoreyshi, and G. D. Najafpour, “Adsorption of dichloromethane from aqueous phase using granular activated carbon :isotherm and breakthrough curve measurments," Middle-East Journal of Scientific Research, vol. 5, no. 4, pp. 191-198, 2010.

[9] L. Gales, A. Mendes, and C. Costa, "Equilibrium and heat of adsorption for organic vapors and activated carbons," Carbon, vol. 38, no. 7, pp. 1083-1088, 2000.

[10] C. Long, Y. Li, W. Yu, and A. Li, "Removal of benzene and methyl ethyl ketone vapor: comparison of hypercross linked polymeric adsorbent with activated carbon," Journal of Hazardous Materials, vol. 203-204, pp. 251-256, 2012.

[11] L. Fournel, P. Mocho, R. Brown, and P. le Cloirec, "Modeling breakthrough curves of volatile organic compounds on activated carbon fibers," Adsorption, vol. 16, no. 3, pp. 147-153, 2010.

[12] C. A. Grande, "Advances in pressure swing adsorption for gas separation," ISRN Chemical Engineering, vol. 2012, Article ID 982934, 13 pages, 2012.

[13] K. Rambabu, L. Muruganandam, and S. Velu, "CFD Simulation for separation of carbon dioxide-methane mixture by pressure swing adsorption," International Journal of Chemical Engineering, vol. 2014, Article ID 402756, 7 pages, 2014.

[14] J. A. Wurzbacher, C. Gebald, and A. Steinfeld, "Separation of $\mathrm{CO}_{2}$ from air by temperature vacuum swing adsorption using diamine-functionalized silica gel," Energy \& Environmental Science, vol. 4, no. 9, p. 3584, 2011.

[15] A. L. Chaffee, G. P. Knowles, Z. Liang, J. Zhang, P Xiao, and P. A. Webley, " $\mathrm{CO}_{2}$ capture by adsorption: material and process development," International Journal of Greenhouse Gas Control, vol. 1, no. 1, pp. 11-18, 2007.

[16] F. Salvador, N. Martin-Sanchez, R. Sanchez-Hernandez, M. J. Sanchez-Montero, and C. Izquierdo, "Regeneration of carbonaceous adsorbents. Part I: thermal regeneration," Microporous and Mesoporous Materials, vol. 202, pp. 259-276, 2015.

[17] M. A. Sidheswarana, H. Destaillats, D. P. Sullivan, S. Cohn, and W. J. Fisk, "Energy efficient indoor VOC air cleaning with activated carbonfiber (ACF) filters," Building and Environment, vol. 47, pp. 357-367, 2011.

[18] M. J. Jeon and Y. W. Jeon, "Characteristic evaluation of activated carbon applied to a pilot-scale VSA system to control VOCs," Process Safety and Environment Protection, vol. 112, pp. 327-334, 2017.

[19] A. Kane, S. Giraudet, J. B. Vilmain, and P. Le Cloirec, "Intensification of the temperature swing adsorption process with a heat pump for the recovery of dichloromethane," Journal of Environmental Chemical Engineering, vol. 3, no. 2, pp. 734-743, 2015. 
[20] K. S. Hwang, D. K. Choi, S. Y. Gong, and S. Y. Cho, “Adsorption and thermal regeneration of methylene chloride vapor on activated carbon bed," Chemical Engineering and Processing, vol. 46, pp. 1111-1123, 1998.

[21] L. Li, Z. Liu, Y. Qin, Z. Sun, J. Song, and L. Tang, "Estimation of volatile organic compound mass transfer coefficients in the vacuum desorption of acetone from activated carbon," Journal of Chemical \& Engineering Data, vol. 55, no. 11, pp. 4732-4740, 2010.

[22] S. Brunauer, P. H. Emmett, and E. Teller, "Adsorption of gases in multimolecular layers," Journal of the American Chemical Society, vol. 60, no. 2, pp. 309-319, 1938.

[23] J. A. Delgada and A. E. Rodrigues, "Analysis of the boundary conditions for the simulation of the pressure equalization step in PSA cycles," Chemical Engineering Science, vol. 63, no. 18, pp. 4452-4463, 2008.

[24] M. F. Edwards and J. F. Richardson, "Gas dispersion in packed beds," Chemical Engineering Science, vol. 23, no. 2, pp. 109123,1968

[25] R. B. Bird, W. E. Stewart, and E. N. Lightfoot, "Transport phenomena," AIChE Journal, vol. 7, no. 2, pp. 5J-6J, 1961.

[26] M. Lei, C. Vallires, G. Grevillot, and M. A. Latifi, "Modeling and simulation of a thermal swing adsorption process for $\mathrm{CO}_{2}$ capture and recovery," Industrial and Engineering Chemistry Research, vol. 52, no. 22, pp. 7526-7533, 2013.

[27] J. Xiao, Y. Peng, P. Benard, and R. Chahine, "Thermal effects on breakthrough curves of pressure swing adsorption for hydrogen purification," International Journal of Hydrogen Energy, vol. 41, no. 19, pp. 8236-8245, 2015.

[28] F. Rezaei, S. Subramanian, J. Kalyanaraman, R. P. Lively, Y. Kawajiri, and M. J. Realff, "Modeling of rapid temperature swing adsorption using hollow fiber sorbents," Chemical Engineering Science, vol. 113, pp. 62-76, 2014.

[29] A. P. D. Wasch and G. F. Froment, "Heat transfer in packed beds," Chemical Engineering Science, vol. 27, no. 3, pp. 567576, 1972.

[30] S. Yagi, D. Kunii, and N. Wakao, "Studies on axial effective thermal conductivities in packed beds," AIChE Journal, vol. 6, no. 4, pp. 543-546, 1960.

[31] K. Daeho, S. Ranjani, and T. B. Lorenz, "Optimization of pressure swing adsorption and fractionated vacuum pressure swing adsorption processes for $\mathrm{CO}_{2}$ capture," Industrial \& Engineering Chemistry Research, vol. 44, pp. 8084-8094, 2005.

[32] J. Zhang, P. A. Webley, and P. Xiao, "Effect of process parameters on power requirements of vacuum swing adsorption technology for $\mathrm{CO}_{2}$ capture from flue gas," Energy Conversion and Management, vol. 49, no. 2, pp. 346-356, 2008. 


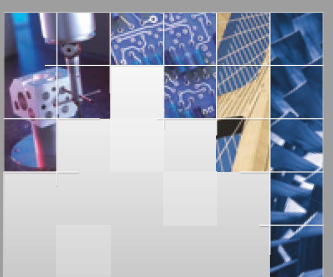

\section{Enfincering}
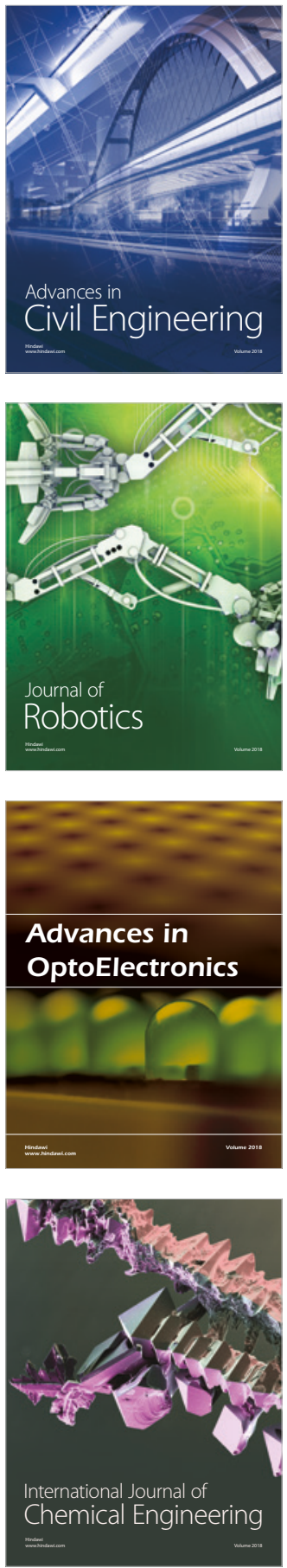

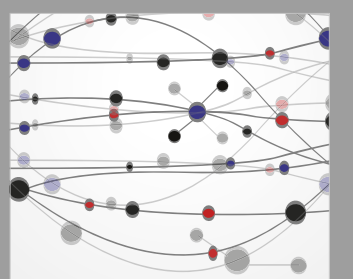

\section{Rotating \\ Machinery}

The Scientific World Journal

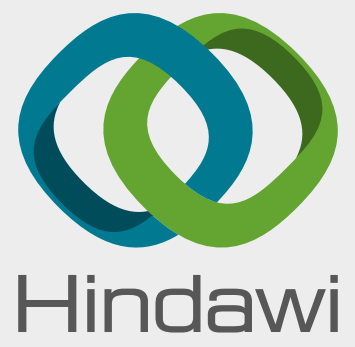

Submit your manuscripts at

www.hindawi.com
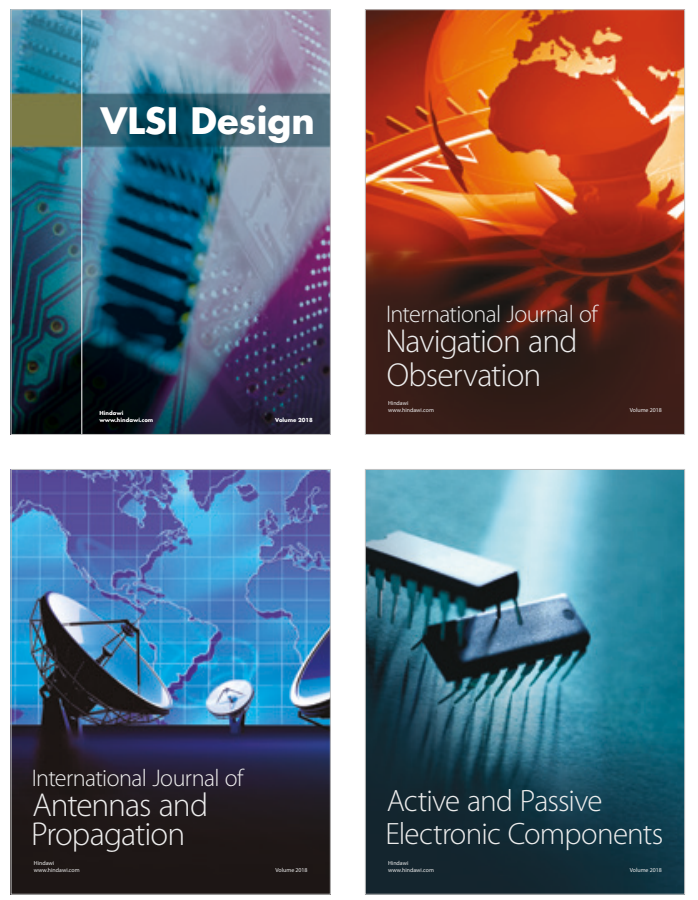
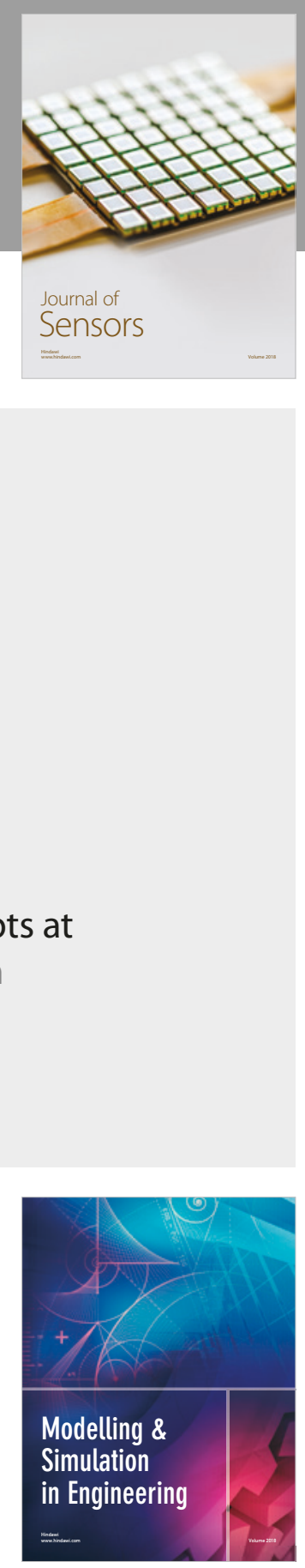

\section{Advances \\ Multimedia}
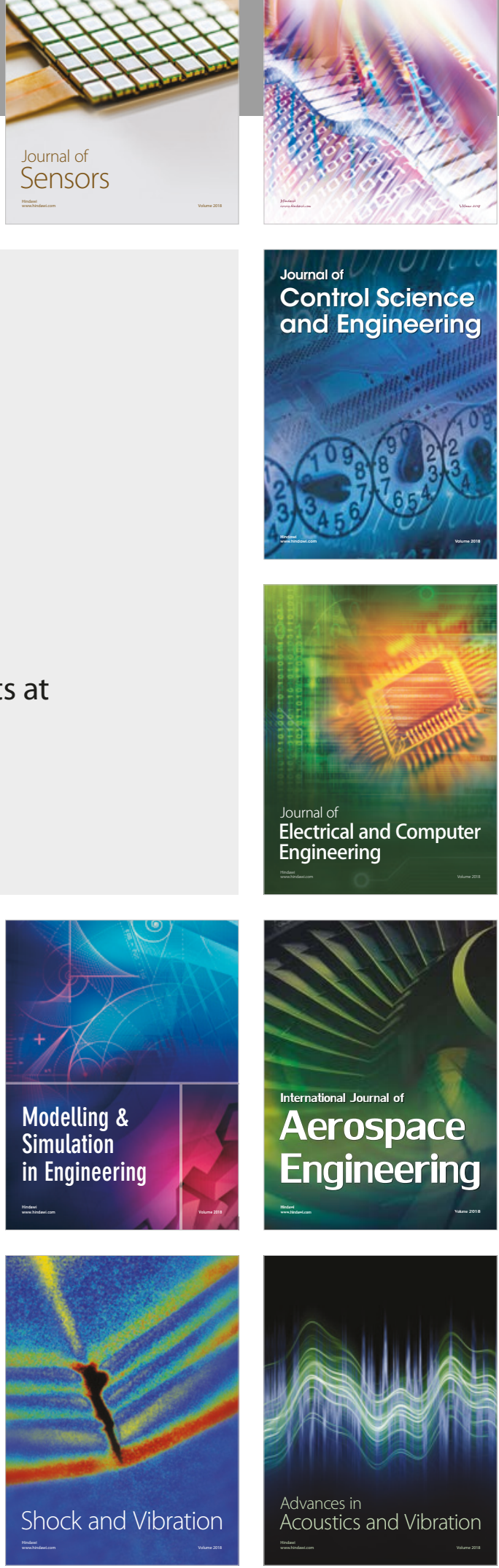